\title{
PTEROSAUR BODY MASS ESTIMATES FROM THREE-DIMENSIONAL MATHEMATICAL SLICING
}

\author{
DONALD M. HENDERSON \\ Royal Tyrrell Museum of Palaeontology, P. O. Box 7500, Drumheller, Alberta, Canada, T0J 0Y0, don.henderson@gov.ab.ca
}

\begin{abstract}
Body masses for 14 species of pterosaur spanning four orders of magnitude were estimated using threedimensional, digital models. The modeled taxa comprised seven paraphyletic 'rhamphorhynchoids': Anurognathus ammoni, Dimorphodon macronyx, Eudimorphodon ranzii, Jeholopterus ningchengensis, Preondactylus buffarinii, Rhamphorhynchus muensteri, and Sordes pilosus; and seven pterodactyloids: Anhanguera santanae, Dsungaripterus weii, Pteranodon longiceps, Pterodaustro guinazui, Pterodactylus sp., Quetzalcoatlus northropi, Tupuxuara longicristatus. The reliability of the mass estimation methods were tested with equivalent models of six extant species of bird with masses that spanned three orders of magnitude. The close agreement between model bird mass estimates and those of the living forms provides a level of confidence in the results obtained for the extinct pterosaurs. The masses of the axial body regions (tail, trunk, neck, head), limbs, and patagia of the pterosaurs were individually estimated and distinct differences in relative body proportions were found between species. Allometric relationships between body length and wingspan and body mass were derived for 'rhamphorhynchoids' and pterodactyloids to facilitate the estimation of body masses for other pterosaurs known from incomplete material, and these relationships also highlight differences in phyletic shape change between the two groups. The estimated mass for the largest pterosaur known, Quetzalcoatlus northropi, exceeds the previous highest estimates by more than $100 \%$, and it is argued that this extremely large pterosaur is better interpreted as a secondarily flightless form.
\end{abstract}

\section{INTRODUCTION}

Pterosaurs are among the most unusual of extinct vertebrates with their apparently ultra-light skeletal construction, flight membranes supported on a single, hypertrophied digit, and large, often bizarre, skulls and crests (Wellnhofer, 1991a; Unwin, 2006). However, pterosaurs were an extremely successful group of archosaurs that ranged from the Late Triassic to the end of the Cretaceous, were the first vertebrates to achieve powered flight, and were diverse enough to occupy a range of ecological niches (Unwin, 2006; Witton, 2008). Pterosaurs have intrigued natural historians for more than two centuries (Cuvier, 1801), and with new kinds of pterosaur fossils, e.g., eggs and embryos (Chiappe et al., 2004; Ji et al., 2004; Wang and Zhou, 2004), and soft tissues (Martill and Unwin, 1989; Lu, 2002), as well as new taxa continually being discovered and identified (e.g., Stecher, 2008; Witton, 2009), interest in these animals continues undiminished.

Knowing the body mass of an animal enables inferences about various aspects of its biology such as physiology (metabolic rate, breathing, digestion times, etc.), mechanical requirements and construction of the skeleton, generation times, reproductive and growth strategies, population densities, ecological niches, and modes of locomotion (Schmidt-Nielsen, 1984). Consequently, there has been much interest in estimating the masses of animals as unusual as pterosaurs, especially in terms of their ability to fly and their possible flight styles, both of which are intimately related to body mass (e.g., Heptonstall, 1971; Bramwell and Whitfield, 1974; Brower and Veinus, 1981; Alexander, 1989, 1998; Hazlehurst and Rayner, 1992;). Given their unusual body shapes and, in many cases, extremely large size, the mass estimates for even a single species of pterosaur have spanned a wide range. For example, mass estimates for an adult Pteranodon longiceps from the Late Cretaceous of Kansas have been as low as $9.1 \mathrm{~kg}$ (Hankin and Watson, 1914), or as high as $50 \mathrm{~kg}$ (Paul, 2002), although some of this difference can be explained by differences in the size of the adult specimens used for the estimate.
For the largest, albeit poorly known pterosaur, Quetzalcoatlus northropi, the mass estimates are even more disparate, having ranged from $64 \mathrm{~kg}$ (MacCready, 1985) to $250 \mathrm{~kg}$ (Paul, 2002). An even higher estimate of $440 \mathrm{~kg}$ was provisionally calculated by Greenewalt (1975), but was quickly rejected by that author in the same paper as being unrealistic.

The actual methods used by some authors to estimate the masses of pterosaurs are often a bit vague (e.g., Heptonstall, 1971; Alexander, 1989; Paul, 2002; Chatterjee and Templin, 2004), or illustrations of the geometric models used to arrive at the actual mass estimates are lacking (e.g., Brower and Veinus, 1981). However, there are several notable counter examples. Witton (2008) made estimates of the masses of selected pterosaur skeletons, and then proceeded to estimate pterosaur body masses using a regression relationship between skeletal mass and body mass derived from extant birds (Prange et al., 1979). Unfortunately, he did not supply illustrations of the skeletons and the geometric forms used to represent them, so it is difficult to judge the quality of restorations that supplied the masses that went into the regression equations. Prondvai et al. (2008), in a careful analysis of the mass of Rhamphorhynchus, also used the Prange et al. scaling relationship, but with an accurate digital 3D model of the skeleton as the starting point. These authors also generated a 3D digital restoration of entire body to estimate its mass. Additionally, they included a calculation to account for the mass of the wing membranes. Regrettably, as this latter report was a conference abstract, no illustrations were provided of the models used. Bramwell and Whitfield (1974) presented a method where they partitioned the head and body of Pteranodon longiceps into a series of regular geometric shapes such as cones and cylinders. These shapes were then adjusted (reduced) to account for the differing amounts of air space within the different parts of the animal. Multiplying the remaining volumes by the density of water (1000 g/liter), and summing the results, they got a more precise estimate of body mass than would have been obtained by using a single bulk density for the whole animal. Given their interest 
in the flight characteristics of Pteranodon longiceps, Bramwell and Whitfield (1974) also estimated the center of mass of their model, and found it to be close to the center of lift estimated for the wing membranes. Hazlehurst (1991) did a similar sort of geometric decomposition of a pterosaur body, but extended the method by developing a series of scaling relationships between the lengths of body components (e.g., head, trunk, limb, and arm bones) and their associated volumes to enable rapid estimations of the volumes of these body parts for different species of pterosaurs. These volumes were then multiplied by an average density value, $730 \mathrm{~g} /$ liter, derived from an analysis of bird densities. Both Bramwell and Whitfield (1974) and Hazlehurst (1991) provided detailed illustrations of the shapes used to derive their mass estimates.

The present study is an attempt to provide estimates of the masses, centers of mass, and wing loadings for a range of pterosaurs using modern illustrations, as well as supplying details of the relative mass fractions of the components of the models. The masses are estimated using the actual contours of the restorations, rather than fitting standard geometric shapes such as cones and cylinders. Additionally, unlike many previous reports on the masses of pterosaurs, the reliability of the methods employed are tested by predicting the masses of models of six living birds for which published mass and body measurements exist.

\section{MATERIALS AND METHODS}

\section{Generation of Bird Models}

Although bats, with their membranous wings, might seem more appropriate extant analogues of membrane-winged pterosaurs, birds were chosen instead for several reasons. Birds and pterosaurs are both members of the clade Archosauria (Diapsida) (Benton, 1997), and each would have inherited a similar basic body architecture from a common ancestor. Both birds and pterosaurs show evidence for extensive pneumatization of their axial and appendicular skeletons (Bonde and Christiansen, 2003; Claessens et al., 2009). Birds breathe with a highly efficient, flow-through lung ventilated with a system of abdominal, thoracic, and clavicular air sacs (Proctor and Lynch, 1993), and pterosaurs are interpreted to have had a similar respiratory system (Bonde and Christiansen, 2003; Butler et al., 2009). Both of these latter similarities, pneumatization and air sacs, would have resulted in potentially similar body densities for the two groups. Birds are known to be able to fly, pterosaurs are inferred to have been able to fly, and this common mode of locomotion would allow for the inference of similarities in the amounts of muscle and body mass distribution (e.g., well-developed pectoral muscles, reduced intrinsic limb muscles, and a center of mass situated anteriorly in the trunk region). Lastly, the largest extant flying bird, the Kori Bustard (Ardeotis kori), can have a body mass of up to $16 \mathrm{~kg}$ (Alexander, 1998), similar to that estimated for some of the largest pterosaurs (see Results). In contrast, bats are members of the clade Synapsida, which diverged from Diapsida sometime in the Carboniferous (Benton, 1997), resulting in a wide phylogenetic and anatomical gulf between bats and pterosaurs. Bats do not show skeletal pneumatization. They ventilate their lungs with a tidal flow driven by a muscular diaphragm. Bats have four of the manual digits supporting the flight membranes, unlike the single wing-finger of pterosaurs. This different form of wing support, when compared to that of pterosaurs, could result in differences in the musclulature and skeletal construction in the region of the chest and shoulders between the two groups. The largest bats, species commonly known as 'flying foxes' (Pteropus spp.), attain a maximum body mass of $1.6 \mathrm{~kg}$ (Nowak and Paradiso, 1983), which is just one tenth that of the Kori Bustard.
Models of six different species of birds were used to test the methods of mass estimation, and these are illustrated in Figure 1 in lateral and dorsal views as 'wire-frame' models. These 'wire-frame' models were generated using the mathematical slicing method presented by Henderson (1999), and this method facilitates the inclusion of smaller surfaces within larger ones to account for lungs or other such cavities within the body. Although not shown in Figure 1, the limb contours were shaped as accurately as possible in both lateral and anterior views to properly reflect the presence and absence of muscle along the limb (e.g., the bulging, muscular, proximal region of the shin followed by a more slender, tendon-bearing, distal region). The arm densities were set to $900 \mathrm{~g} /$ liter based on observations of pneumatization of the arm bones and surrounding tissues (Proctor and Lynch, 1993), whereas the legs were set to $1000 \mathrm{~g} /$ liter.

Both lungs and air sacs were incorporated into the bird models. Lung volumes were estimated for each model the scaling relationship established by Schmidt-Nielsen (1984) between body mass and lung volume for birds, whereas air sacs were accounted for with a reduced density in the trunk and neck regions (see Assignment of Body Densities below). As the final body mass is dependent on the volume of the lung cavity, an iterative approach was used to get a final lung volume estimate using the following two equations with body mass measured in kilograms:

$$
\begin{aligned}
\operatorname{lung}_{\text {_vol }} & =29.6 \cdot\left(\text { body_mass }_{0}\right)^{0.94} \\
\text { lung_vol }_{n+1} & =29.6 \cdot\left(\text { body_mass }_{0}-\frac{\text { lung_vol }_{n}}{1000}\right)^{0.94}
\end{aligned}
$$

Where body_mass ${ }_{0}$ is the estimated mass of the body without the lung cavity included, and lung_vol ${ }_{0}$ is the initial volume estimate done with Equation (1). This first lung volume estimate, measured in milliliters, is then used to decrease the body mass by the appropriate amount, and provide a second, improved estimate of lung volume in Equation (2). The cycle of improving the estimate using Equation (2) is carried out until the difference between two consecutive lung volume estimates differs by less than 1 part in 10,000 , and typically takes about 6 iterations.

Figure 1 also shows outlines of the feathered wing surfaces of five of the bird models (for flying species). These outlines were used to compute the areas of the wings using the triangular decomposition method developed by Henderson (2002). The area estimates of the wings (left and right) were combined with the ventral projection of the axial body area that lies between the wings (i.e., excluding the projected areas of the tail, neck, and head) to provide a value for the calculation of the wing loading. Wing loading is defined as the animal's weight (mass multiplied by the gravitational acceleration of $9.81 \mathrm{~m} / \mathrm{s}^{2}$ ) divided by the combined relevant areas of the axial body and the wings (Alexander, 1989).

\section{Generation of Pterosaur Models}

Figures 2 and 3 present lateral and dorsal views of the "wireframe' models of the 14 pterosaurs considered in this study-7 'rhamphorhynchoids' and 7 pterodactyloids, along with twodimensional, dorsal views of the restored wing membranes From the recent cladogram provided by Unwin (2003) the pterodactyloids can be seen to form a monophyletic group, whereas the 'rhamphorhynchoids' form a paraphyletic series of sister taxa to the more derived pterodactyloids. 'Rhamphorhynchoids' first appeared in the Upper Triassic, and persisted into the Lower Cretaceous, while the pterodactyloids, first appearing the Upper Jurassic, persisted to the end of the Cretaceous (Unwin, 2004). The sources used to generate these models are listed in Table 1, 
A
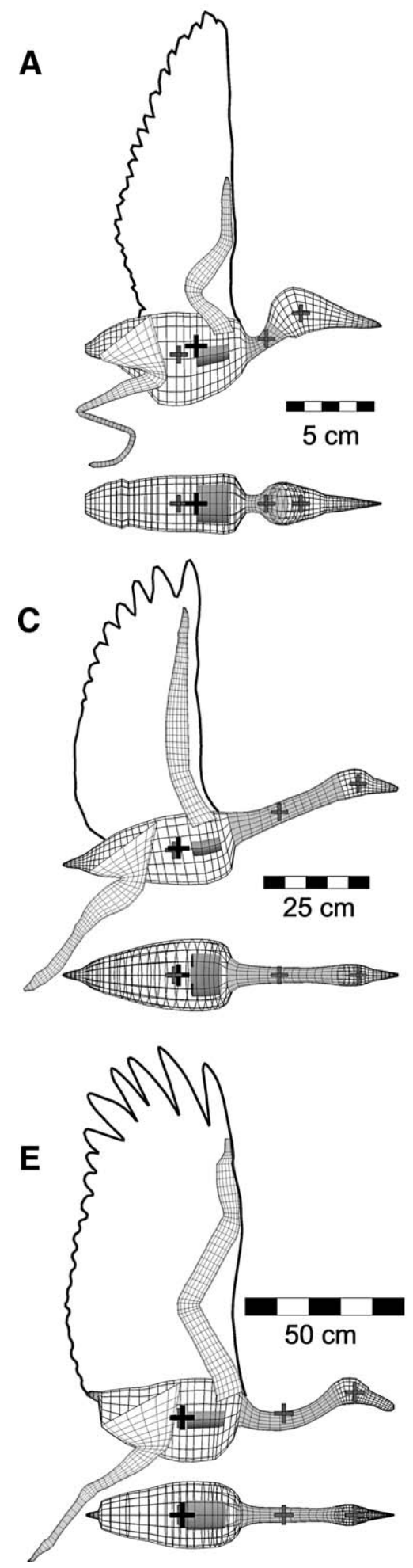

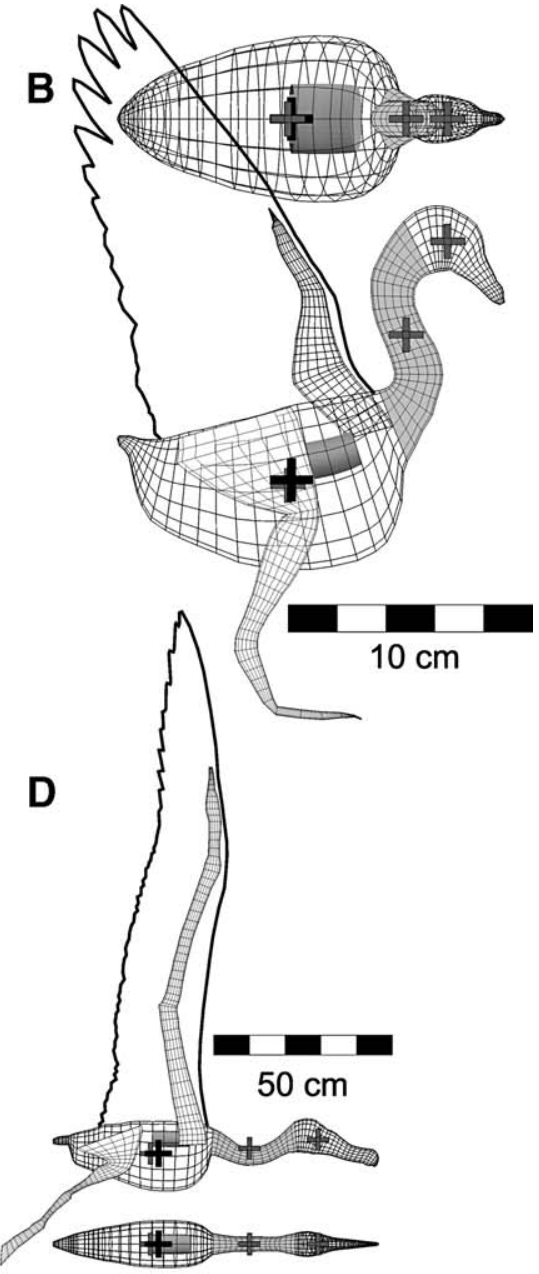

FIGURE 1. Isometric views of the six bird models as three-dimensional, wire-frame models, that were used to validate the mass estimation methods applied to the pterosaur models. The illustrated wing outlines were used to calculate wing loadings. Taxa are arranged in order of increasing mass. The identification of each illustrated specimen is followed by its wingspan and the citation for the source of the images used for the generation of the model. A, European Starling (Sturnus vulgaris), $39.3 \mathrm{~cm}$, Jenkins et al. (1988). B, Rock Dove [Pigeon] (Columba livia), $45.2 \mathrm{~cm}$, Proctor and Lynch (1993). C, Canada Goose (Branta canadensis), 1.36 m, www.karencarr.com. D, Wandering Albatross (Diomedea exulans), $3.16 \mathrm{~m}$, Paul (2002). E, Great Bustard (Otis tarda), 2.49 $\mathrm{m}$, Paul (2002). F, Ostrich (Struthio camelus), height $=1.67 \mathrm{~m}$, Deeming et al. (1996). The dark gray '+ + 's highlight the centers of mass of the three principal body regions (trunk, neck, and head). The black ' + ' indicates the center of mass of the whole body and includes the effects of the lungs (indicated as shaded grey volumes in the chest regions). along with associated wingspans and body length (tip of tail to tip of snout) to provide an idea of physical sizes. Most of the models were derived from illustrations in semi-popular works (e.g., Langston, 1981; Wellnhofer, 1991a; Unwin, 2006). The use of these sources is justified for the several reasons. The authors of these works are recognized authorities on pterosaurs, and it is expected that any restorations of pterosaurs in their books and articles would be as scientifically accurate as possible, and many of the restorations in them are taken directly from the primary literature. Most pterosaur fossils are badly crushed and rarely complete, and any restoration of these animals will always have a level of uncertainty associated with it, no matter who does 
TABLE 1. Sources used for the construction of the pterosaur models of Figures 2 and 3, and the abbreviations used as identification labels on subsequent plots.

\begin{tabular}{|c|c|c|c|c|}
\hline & Model form source & Axial body length $(\mathrm{m})$ & Wingspan (m) & $\begin{array}{c}\text { Plot label } \\
\text { abbreviation }\end{array}$ \\
\hline \multicolumn{5}{|c|}{ 'Rhamphorhynchoids' } \\
\hline Anurognathus ammoni & Bennett (2007b) & 0.0645 & 0.216 & A.a \\
\hline Dimorphodon macronyx & Wellnhofer (1991a), Unwin (2006) & 1.01 & 1.42 & D.m \\
\hline Eudimorphodon ranzii & Wellnhofer (1991a), Unwin (2006) & 0.800 & 1.00 & E.r \\
\hline Jeholopterus ninchengensis & Li et al. (2008) & 0.202 & 0.773 & J.n \\
\hline Preondactylus buffarinii & Wellnhofer (1991a) & 0.400 & 0.446 & P.b \\
\hline Rhamphorhynchus muensteri & Wellnhofer (1991a) & 1.01 & 1.62 & R.m \\
\hline \multirow{2}{*}{\multicolumn{5}{|c|}{ Pterodactyloids }} \\
\hline & & & & \\
\hline & $\begin{array}{l}\text { Wellnhofer (1991b) } \\
\text { Wellnhofer (1991a) }\end{array}$ & 1.11 & 4.09 & A.s \\
\hline $\begin{array}{l}\text { Dsungaripterus weii } \\
\text { Pteranodon longiceps }\end{array}$ & $\begin{array}{l}\text { Wellnhofer (1991a) } \\
\text { Bennett (1991) }\end{array}$ & 1.41 & $\begin{array}{l}3.60 \\
5.34\end{array}$ & D.w \\
\hline $\begin{array}{l}\text { Pterodactylus sp. } \\
\text { Pteps }\end{array}$ & $\begin{array}{l}\text { Bennett (1991) } \\
\text { Wellnhofer (1991a) }\end{array}$ & $\begin{array}{l}1.91 \\
0.715\end{array}$ & $\begin{array}{l}5.24 \\
1.48\end{array}$ & $\begin{array}{l}\text { P.I } \\
\text { P.sp }\end{array}$ \\
\hline Pterodaustro guinaz ui & Wellnhofer (1991a) & 0.696 & 1.23 & P.g \\
\hline Ouetzalcoatlus northropi & Wellnhofer (1991a), Langston (1981) & 6.36 & 11.2 & Q.n \\
\hline Tupuxuara longicristatus & Hasegawa et al. (2006) & 1.92 & 4.11 & T.1 \\
\hline
\end{tabular}

the restoration. Nor is there an absolute, final mass estimate for any species of animal, there will always be a range of variation about a mean value, and there exists the possibility of differences between males and females. Lastly, no animal has a constant mass all of its adult life. The vagaries of its food supply over the course of a year, as well as the reproductive status of a female individual, will be another source of variation in body mass. Given the inherently variable nature of body mass, and the uncertainties associated with the restoring animals as unusual as pterosaurs, the use of the skeletal forms and body restorations from works such as Wellnhofer (1991a) would seem to be adequate for the present broad study of pterosaur masses.

Axial body and limb meshes were generated for the pterosaurs using essentially the same methods as were used for the birds. The only differences were in the generation of the widths and depths of the limb segments, and in the treatment of patagia. Given the generally two-dimensional nature of pterosaur fossils (Unwin, 2006), there will be some uncertainty about the actual transverse dimensions of the fleshed-out arms and legs. A general scheme was implemented where the depths and widths of muscled limb segments were estimated using the proportions of the first three segments of the limbs. For the arms, the basal width (fore and aft direction at right angles to the long axis of the humerus) was set as one quarter of the average length of the humerus, ulna, and fourth metacarpal. The basal depth (dorsoventral distance perpendicular to the bone) was set as one half of the basal width. This depth and width pair were used as the semi-major and semi-minor radii to form limbs with elliptic crosssections. At each subsequent joint of the arm the width and depth were reduced by a factor of two thirds. This results in a rapidly tapering series of flesh outlines. The same process was used for the legs, but with basal width set as one quarter of the average length of the femur, tibia, and pes. The reduction factor for decreasing the depths and widths with distance was set to 0.55 , because the pedes do not become as slender as the distal wing phalanges. The density of the muscled portions of the arms was set at $900 \mathrm{~g} / \mathrm{liter}$ in light of the hollow nature of the bones, and the evidence for air sacs in the arms (Claessens et al., 2009). The leg density was set at $1000 \mathrm{~g} /$ liter. Neither the cranial crests seen in the models of pterodactyloids nor the teeth of Pterodaustro guinazui were included in any of their mass determinations. Lacking any direct fossil evidence for the size and extent of their lungs, it was felt that it was most parsimonius to assume a lung structure for pterosaurs that was similar to that of birds, in light of their common ancestry. Lung volumes were determined using the same scaling relationship and equations that were used for the birds.
The three components of the pterosaurian flight membranecruropatagium, cheiropatagium, and propatagium-had their individual areas determined using the same triangular decomposition method as was used for the bird wing areas (Henderson, 2002). This method also supplies the centroids of the computed areas, and these are shown as black ' + ' signs on the wing membranes of Figures 2 and 3. The areal extent of the patagia, and their degree of attachment to the hindlimbs, is contentious (Hazlehurst and Rayner, 1992). However, based on the numerous examples showing the membrane attached to lower legs and ankles cited in Witton (2008), all the cheiropatagia were extended down to the ankle. In keeping with the traditional view, and from the arguments of Bennett (2007a), the pteroid bone was directed towards the body, and not anteriorly as has been suggested (Wilkinson et al., 2006). This orientation avoids exaggerating the area of the propatagium and displacing the wing centroid anteriorly. The volumes of the patagia were calculated by multiplying the area by a constant thickness of $0.015 \mathrm{~cm}$ and $0.03 \mathrm{~cm}$ for 'rhamphorhynchoids' and pterodactyloids, respectively, using the data on the thicknesses of the wing membranes of the largest living bat, the Indian flying fox (Pteropus giganteus) from Bramwell and Whitfield (1974), which they found to have an average value of $0.015 \mathrm{~cm}$. An important point to note is that membrane thickness may scale (non-linearly) with body mass to maintain a constant stress within the membrane (C. Palmer, pers. comm.). As a result, any chosen membrane thickness must be regarded as a first approximation to the actual value for any given animal.

\section{Assignment of Body Densities}

The forms of the bodies and limbs of the models are defined by the cross-cutting slices, and each pair of consecutive slices delineates a three-dimensional slice, or 'slab,' of a model. Each individual slab of a model can have a density that differs from that of its neighbors, and this enables a more precise representation of regional density variation within a model. For the bird models, the mean density of the trunk was set at $850 \mathrm{~g} / \mathrm{liter}$, based on the observation that the air sacs within a bird represent about $15 \%$ of the trunk volume (Proctor and Lynch, 1993), and the fact that typical soft tissue density is same as that of water at $1000 \mathrm{~g} /$ liter. The trunk region for the birds is considered here to be the combination of the caudal, pelvic, and thoracic regions. The density of the head and neck were set at $300 \mathrm{~g} /$ liter, using data from the neck of a domestic goose (Anser domesticus) (Bramwell and Whitfield, 1974). The necks of all the models shown in Figures 1, 2, and 3 have been colored a medium grey to highlight the boundaries 


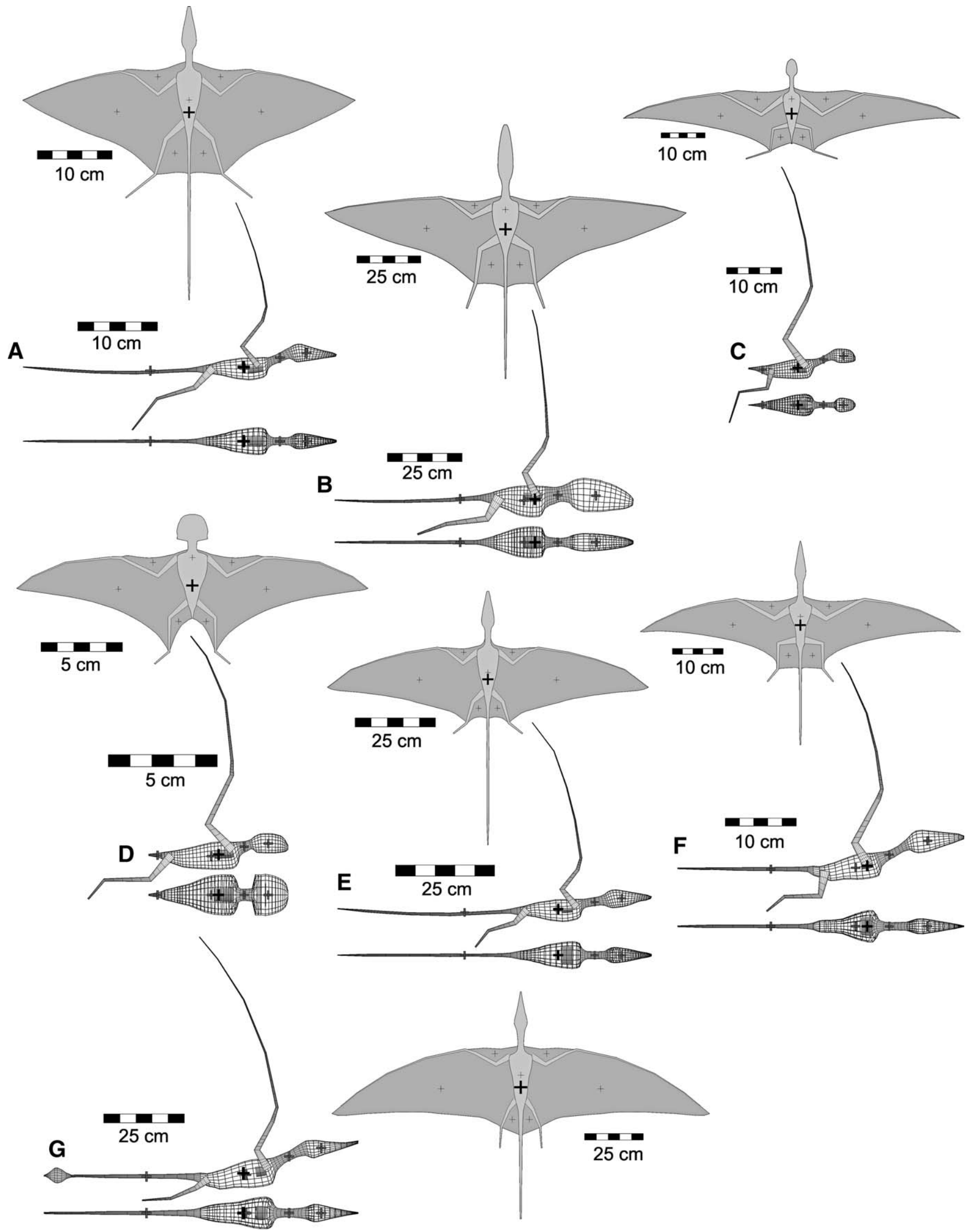


between the low-density neck and higher-density trunk. Summing the results of multiplying the different volumes representing the components of the bodies by their respective densities provides the mass estimates for the models.

The regional densities for the axial bodies of the pterosaur models were set using the observed similarities of the pneumatized skeletons of birds and pterosaurs (Wellnhofer, 1991a; Bonde and Christiansen, 2003; Unwin, 2006), as well as the arguments for an elevated metabolic rate that would have demanded efficient respiration via a system of air sacs and lungs similar to that of birds (Heptonstall, 1971; Brower and Veinus, 1981; Hazlehurst and Rayner, 1992; Bonde and Christiansen, 2003). The trunk region (pelvic and thoracic) was set to $850 \mathrm{~g} / \mathrm{liter}$, and the head and neck were set to $300 \mathrm{~g} /$ liter. Although their volumes were not specifically determined, the expectation is that the nasal and oral cavities, and any cranial sinuses, would have been extensive in the skulls of pterosaurs given the high degree of pneumaticity in their skeletons as a whole (Claessens et al., 2009), thus heads were set to a low density. Although there may have been decreases in body and skull density with increasing body size in pterosaurs, direct, reliable evidence of this sort of change is lacking. The most parsimonius assumption, given the current state of our knowledge of these animals and their fossil remains, is to assume densities similar to that of birds. The long bony tails of the 'rhamphorhynchoids' had their densities set to $1000 \mathrm{~g} / \mathrm{liter}$, whereas those of the more derived pterodactyloids were set to $850 \mathrm{~g} /$ liter in light of evidence for more extensive pneumatization (Claessens et al., 2009). The patagial masses were computed by multiplying their volumes by an appropriate density. The densities of the patagia were assumed to be slightly greater than that of water, based on the presence of muscles, blood vessels, and actinofibrils within the wing membranes (Martill and Unwin, 1989; Wellnhofer, 1991a), and set to $1100 \mathrm{~g} /$ liter. Although the density assigned to the patagia of the pterosaurs is higher than any of the densities assigned to other parts of any of the models, and despite their large areal extent relative to the axial body, the extreme thinness of the patagia minimizes their contribution to the total mass and any estimate of average body density.

\section{RESULTS}

\section{Bird and Pterosaur Mass Estimates}

Appendix 1 presents the computed total body masses for the bird models, along with a breakdown of the component masses and their relative fractions of the total. Figure 4A and B present the tabulated results in graphical form along with the observed ranges of variation taken from the data sources listed in Appendix 2. The natural range of variation seen in the masses of the birds modeled is extensive, e.g., the Canada goose can range from 3 to $9 \mathrm{~kg}$. This fact should be kept in mind when assessing the masses estimated for extinct animals, especially ones as unusual as pterosaurs. Given the potential for different poses of the long bird neck, and the subsequent effects on body length, it was felt that the only way to reliably estimate total body length was to compute it as the 'path length' along the mathematically central axis of each model. It is this length that is used as the independent variable in the upper plot of Figure 4. Two of the bird model masses lie slightly below the observed ranges- the ostrich and the pigeon. This is easily explained because these models are of slightly smaller stature than the published ranges for adult birds. The masses of the birds used here span three orders of magnitude and represent a variety of ecological niches, yet all the model masses lie within, or close to the observed ranges, despite all having the same density assignments. This even applies to the terrestrial (non-flying) Ostrich (Struthio camelus). It is important to note that there is not a single density value for birds in general, that the physical condition of an individual can vary (e.g., more or less body fat at different times of the year), and that there exists a correlation between mode of life and body density, with long distance flyers having a lower density than short distance flyers (Witton, 2008).

The method of Henderson (1999) also enables the calculation of the center of mass (CM) of a body model, and the CMs of the various bird body regions (trunk, head and neck) are indicated in the relevant figures with dark grey ' + ' signs. The CMs of entire bodies are shown with a black ' + ' sign. An indication of the degree of plausibility of the assigned density distributions (and the modeled body and lung shapes) is the location of the whole body $\mathrm{CM}$ in the two standing models-pigeon and ostrich (Fig. 1). Here the CMs lie centered above the supporting feet, indicating that these birds are balanced and able to stand normally. The combined masses of their heads and necks represent less that $3 \%$ of their total mass in these two birds (Appendix 1), and their necks could be moved about with minimal displacement to the $\mathrm{CM}$ and no resulting loss of balance.

With the mathematical slicing method, in combination with the choice of densities for the various body regions, giving reasonable results for the bird models, the pterosaur models can be analyzed. Figure 4C and D present plots of the estimated body masses for the pterosaurs as functions of both body length and wingspan. These latter two sets of data are summarized in Table 1 , and the body mass data are presented in Table 2 . For consistency with the bird models, body length was also measured as the central axial distance. One noticeable feature is just how extreme Quetzalcoatlus northropi is in terms of size relative to the other pterosaurs. Its body is more than three times longer than that of the next largest pterosaur, Pteranodon longiceps. Its wingspan is, conservatively, twice as wide (Lawson, 1975; Langston, 1981). Most significantly, its estimated body mass is almost 30 times that of $P$. longiceps ( 29.2 to be exact). It should be noted that not all the models represent animals at the same growth stage, i.e., not all are fully adult. In particular, the Anurognathus model is based on a juvenile animal. The wingspan and mass estimates of the taxa in the present study are compared with those of Brower and Vienus (1981), Hazelhurst and Rayner (1992), and Witton (2008) in the table contained in online Supplementary Data 4. As there

\footnotetext{
$\leftarrow$ FIGURE 2. Right lateral and dorsal views of 'rhamphorhynchoid' (non-pterodactyloid) pterosaurs as three-dimensional, wire-frame models used to compute body masses, along with two-dimensional wing reconstructions used for wing loading calculations. A, Preondactylus buffarinii; $\mathbf{B}$, Dimorphodon macronyx; $\mathbf{C}$, Jeholopterus ningchengensis; $\mathbf{D}$, Anurognathus ammoni; $\mathbf{E}$, Eudimorphodon ranzii; $\mathbf{F}$, Sordes pilosus; $\mathbf{G}$, Rhamphorhynchus mиensteri. For the wire-frame views, the dark gray '+'s highlight the centers of mass of the four principal body regions (tail, trunk, neck, and head). The heavy black ' + ' indicates the center of mass of the whole body and includes the effects of the lungs (indicated as shaded grey volumes in the chest regions). The orientations of the forelimbs and hind limbs are only to show their forms, and not an indication of potential range of motion or configuration during flight. For the planar wing reconstructions, the small ' + 's on the wing membranes indicate the centroids of the individual wing regions, while the large black ' + ' marks the centroid of the entire ventral body surface represented by the wing membranes and axial body. Note that the main centroid of a planar view is not the same thing as the center of mass in the wire-frame view. The scales used for the two- and three-dimensional views are not exactly the same due to the resizing of the images to make the best use of figure space. See Table 1 for sources used in constructing the models and the magnitudes of their wingspans and body lengths.
} 

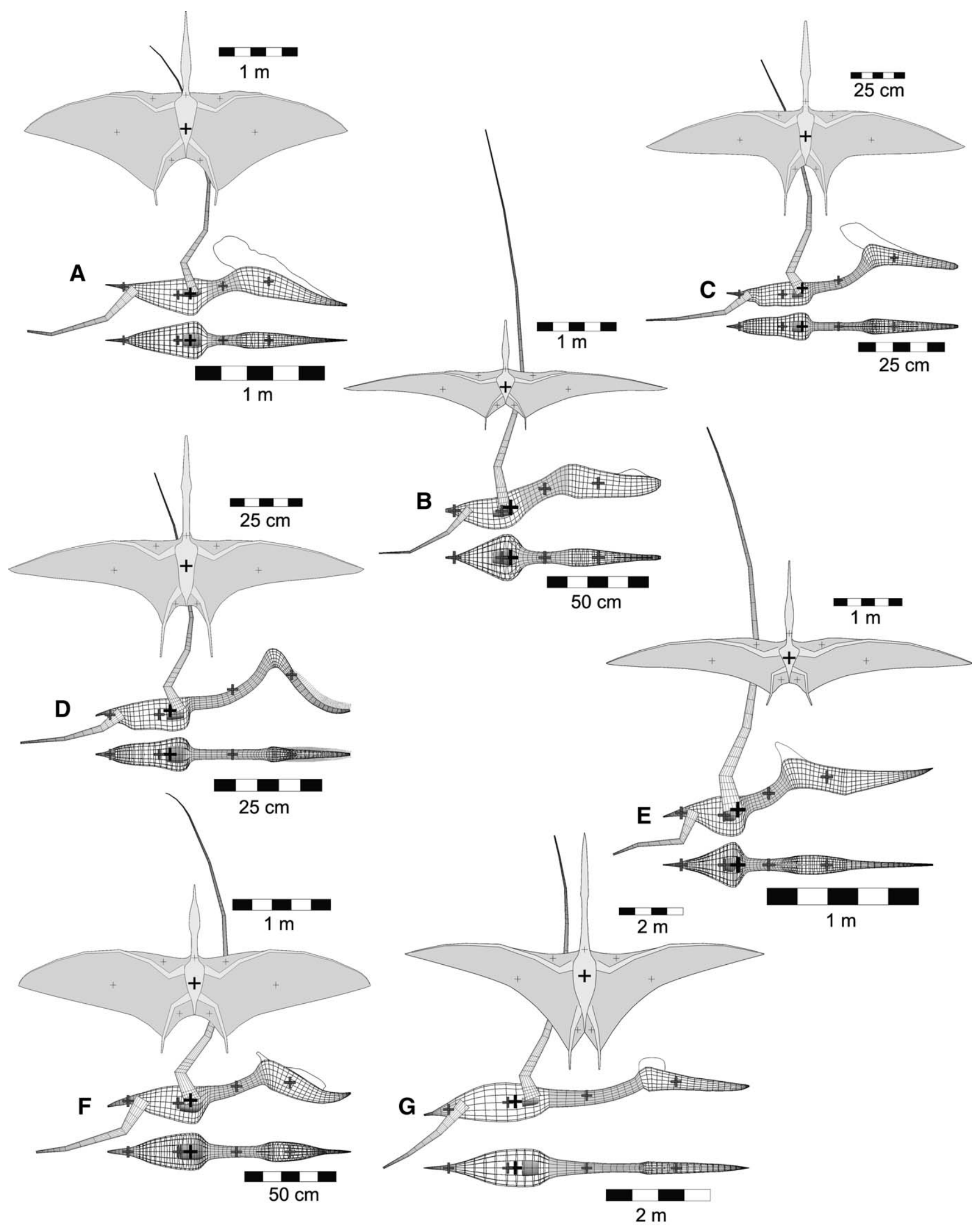

FIGURE 3. Right lateral and dorsal views of pterodactyloid pterosaurs as three-dimensional, wire-frame models used to compute body masses, along with two-dimensional wing reconstructions used for wing loading calculations. A, Tupuxuara longicristatus; B, Anhanguera santanae; $\mathbf{C}$, Pterodactylus sp.; D, Pterodaustro guinaz ui $; \mathbf{E}$, Pteranodon longiceps; F, Dsungaripterus weii $;$ G, Quetzalcoatlus northropi. Details as per Figure 2. 

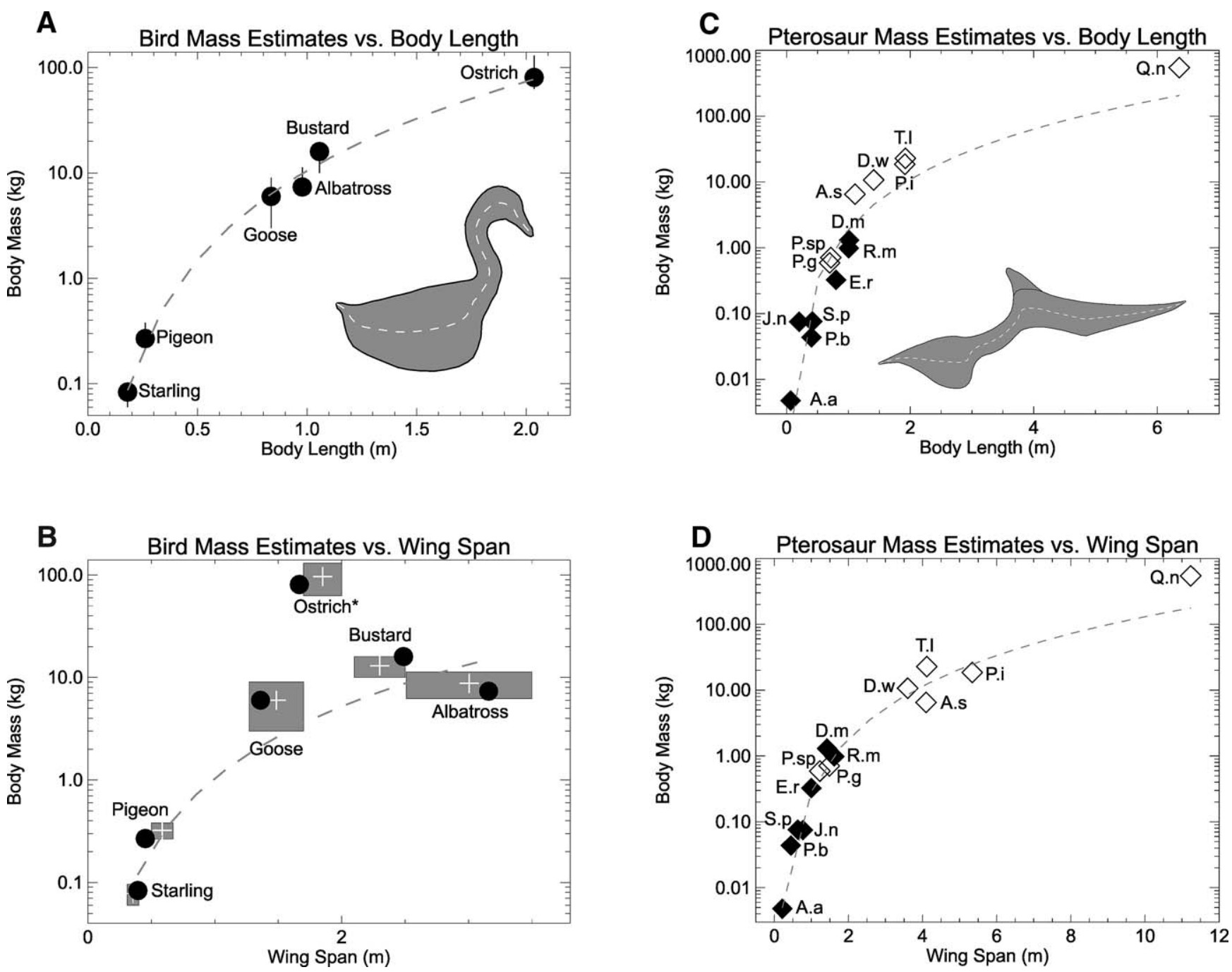

FIGURE 4. Logarithms of estimated total body mass—axial body + limbs - lungs ( + patagia) — determined for the bird and pterosaur models of Figures 1,2, and 3 plotted against body length and wingspan. A, Bird mass versus body length. The vertical bars mark the ranges of observed body masses for the various species, and the inset rock dove (Columba livia) figure shows how body length was defined as the full central axial length of each model. B, Bird mass versus wingspan. The grey boxes mark the observed wingspan ranges (left-right box limits) and the observed mass ranges (top-bottom box limits) for the six species. The white ' + ' signs mark the centers of the boxes (the apparent off-center vertical position is due to the logarithmic vertical axis). C and D, Pterosaur body mass versus body length and wingspan, respectively. Black diamonds show 'rhamphorhynchoids' (non-pterodactyloids) and open diamonds show pterodactyloids. The Pteranodon longiceps inset of the upper figure shows how body length was defined as the full central axial length of each model. The grey dashed lines on each plot are the lines of best fit determined from the regression analyses of Figure 6. See Appendix 1 for model bird mass estimates, and Appendix 2 for observed wingspan and mass ranges used in the construct of the bird plots. See Tables 1 and 2 for a key to the pterosaur plot labels and mass estimates, respectively. Note: For the ostrich in plot B the total height of the model was used instead of wingspan, and the left-right box limits are based on observed heights of sub-adult ostriches (Deeming et al. 1996).

is a range of wingspan (i.e., body size) estimates provided by the different authors for the same animals, an additional column in this table presents these mass estimates rescaled to animals with the same wingspans as presented in the present study.

\section{Sensitivity of Pterosaur Mass Estimates to Body Shape Changes}

With the rare exceptions such as those of the threedimensionally preserved pterosaur fossils from the Brazilian Santana Formation (Martill et al., 1993), most pterosaur skeletons are preserved as flat, two-dimensional objects (Unwin, 2006). This leads to uncertainty as to their original (i.e., in life) shapes, and it is likely that we may never know the true body shape of these animals. A goal to strive for is that any restoration be aero- dynamically and biomechanically plausible, and that it represents an organism that could function based on what we know of extant forms. The main uncertainties come from three sets of dimensions: the transverse widths of the bodies, the depths of the trunk region, and the extent of the ventral parts of the neck and head. Extreme lateral crushing of the fossils eliminates most body width information. The trunk depth uncertainty arises from questions about the configuration and degree of articulation between the ribs and sternum, and new ideas about the mechanics of lung ventilation in pterosaurs (Claessens et al., 2009). The sizes of the trachea, esophagus, and tongue, and the amount of skin and muscle around and below the neck and head lead to uncertainties in these regions. As a check on how sensitive the estimated masses of the pterosaur models were to the restored dimensions, 
TABLE 2. Total masses and component masses for the pterosaur models of Figures 2 and 3.

\begin{tabular}{|c|c|c|c|c|c|}
\hline & Total mass & Axial mass (\%) & Single leg mass ( $\%)$ & Single arm mass (\%) & Patagium mass (\%) \\
\hline \multicolumn{6}{|c|}{ 'Rhamphorhynchoids' } \\
\hline Anurognathus ammoni & 0.00478 & $0.00362(75.7)$ & $7.61 \times 10^{-5}(1.59)$ & $1.11 \times 10^{-4}(2.33)$ & $4.91 \times 10^{-4}(10.3)$ \\
\hline Dimorphodon macronyx & 1.30 & $1.15(88.6)$ & $0.0425(3.27)$ & $0.0291(2.24)$ & $0.0216(1.66)$ \\
\hline Eudimorphodon ranzii & 0.325 & $0.283(87.1)$ & $0.00713(2.19)$ & $0.00801(2.46)$ & $0.0110(3.40)$ \\
\hline Jeholopterus ninchengensis & 0.0750 & $0.0560(74.7)$ & $0.00142(1.89)$ & $0.00497(6.63)$ & $0.00441(5.88)$ \\
\hline Preondactylus buffarinii & 0.0437 & $0.0352(80.7)$ & $0.00127(2.91)$ & $0.000715(1.64)$ & $0.00301(6.90)$ \\
\hline Rhamphorhynchus muensteri & 0.986 & $0.891(90.3)$ & $0.0120(1.22)$ & $0.0231(2.34)$ & $0.0274(2.78)$ \\
\hline Sordes pilosus & 0.0758 & $0.0598(79.0)$ & $0.00215(2.84)$ & $0.00361(4.76)$ & $0.00352(4.65)$ \\
\hline \multicolumn{6}{|c|}{ Pterodactyloids } \\
\hline Anhanguera santanae & 6.52 & $5.70(87.5)$ & $0.0799(1.23)$ & $0.325(4.99)$ & $0.0901(1.38)$ \\
\hline Dsungaripterus weii & 10.7 & $8.21(76.7)$ & $0.490(4.57)$ & $0.746(6.97)$ & $0.151(1.41)$ \\
\hline Pteranodon longiceps & 18.6 & $13.5(72.7)$ & $0.442(2.38)$ & $2.14(11.5)$ & $0.180(0.968)$ \\
\hline Pterodactylus sp. & 0.708 & $0.548(77.5)$ & $0.0202(2.86)$ & $0.0496(7.01)$ & $0.0204(2.88)$ \\
\hline Pterodaustro guinazui & 0.590 & $0.495(84.0)$ & $0.0174(2.95)$ & $0.0257(4.36)$ & $0.0132(2.23)$ \\
\hline Quetzalcoatlus northropi & 544 & $474(87.2)$ & $13.2(2.43)$ & $26.0(4.78)$ & $1.10(0.203)$ \\
\hline$\widetilde{T}$ трихиаra longicristatus & 22.8 & $20.2(88.7)$ & $0.664(2.91)$ & $0.668(2.93)$ & $0.234(1.03)$ \\
\hline
\end{tabular}

All masses are in kilograms with component relative fractions expressed as percentages of the total mass in parentheses. Patagial masses and their relative fractions are for single instances (e.g., the left or right side). See Figure 9 for graphical comparisons of body and limb proportions between models.

the axial bodies of all 14 models were both shrunk and enlarged laterally and ventrally by $10 \%$. The dimensional changes were only applied to the axial body, because it can be seen from $\mathrm{Ta}-$ ble 2 that this region always represents more than $72 \%$ of the body mass, with the average being $82 \%$. The magnitudes of these changes are illustrated graphically using Pteranodon longiceps in Figure 5, and were made proportional to the local depths and widths of the body using the dimensions of the slices that define the body shape. The dorsal profile in lateral view was not altered during these operations, because the presence of the spinal column and associated neural spines provide a reliable guide for any restoration. Nor were the distal halves of the tail or snout adjusted because these regions represent very small portions of the body.

Both pterosaur groups share a consistent change in body mass of approximately $12 \%$ for a $10 \%$ change in the transverse axial dimensions. With the 'rhamphorhynchoids' an additional variable rate of mass change is one that is positively correlated with body size, i.e., the effect of a $10 \%$ difference in body dimensions on estimated body mass is less for a smaller taxon such as Preondactylus buffarinii than it is for a larger taxon such as Rhamphorhynchus meunsteri. In contrast, the pterodactyloids show a virtually constant change of approximately $12 \%$ independent of body size. These differences in the effects of the applied shape change between the two groups (1) may reflect something about the actual body shapes of the living forms and how they varied (or not) as new genera and clades evolved (see Discussion); or (2) may just be artifacts of the restorations used to generate the models. See online Supplementary Data 1 for details of the mass changes for each pterosaur model.

\section{DISCUSSION}

It has been observed that larger, volant birds have lower densities than smaller ones, and aquatic or soaring birds also tend have lower densities (Hamershock et al., 1993). The mass estimates of the models of the great bustard (Otis tarda) and the wandering albatross (Diomedea exulans) lie in the upper regions of the observed ranges, and this may be attributed to overestimates of their densities. Smaller birds such as starlings and pigeons have feather masses that represent $2-3 \%$ of total mass, whereas larger birds such as a herring gull or turkey vulture have feather mass equal to $8-9 \%$ of body mass (Hamershock et al., 1993). Feathers, and their associated masses, were not explicitly included in the bird models, but their inclusion would only have a significant effect on mass estimates of the models of the largest birds. Again, a slight lowering of the limb and axial body densities could be used in these cases (and correspond to the lower densities seen in larger birds) to account for the presence of feathers, and still have the estimated total masses lie within the observed ranges.

The average bulk density (with feathers) for the 12 bird species presented in Table 1 of Hamershock et al. (1993) was found to be $726 \mathrm{~g} /$ liter $(\mathrm{SD}=85.5)$, and this was for species with masses that ranged from a 23-g house sparrow (Passer domesticus) to a 1.8-kg turkey vulture (Cathartes aura). Hazlehurst (1991:appendix 29) found a mean bulk density of $730 \mathrm{~g} /$ liter $(\mathrm{SD}=$ 51.2) for his sample of nine birds, and this covered species that ranged in mass from 24-28 g for a set of chaffinchs (Fringilla coelebs) to $170-240 \mathrm{~g}$ for a set of collard doves (Streptopelia decaocto). The resulting mean density of the birds used in the present study is $806 \mathrm{~g} /$ liter $(\mathrm{SD}=30.1$ ) (Table 3$)$. With the large standard deviations associated with all three of the above samples, the differences between them are not significant. The bulk densities of the 14 pterosaur models (analyzed as two separate groups-'rhamphorhynchoids' and pterodactyloids) were computed for comparison with those of the birds, and are presented in Table 3. At first glance, it would seem that the average densities for the two pterosaur groups match expectations based on their lightly constructed skeletons and predicted modes of life. Both 'rhamphorhynchoids' and pterodactyloids have bulk densities that are lower than those of birds, and the pterodactyloids have lower densities than the 'rhamphorhynchoids.' Anatomical proportions suitable for a gliding mode of flight, and the apparently very light skeletons of the pterodactyloids would seem to corroborate the finding of the lower density for the models of this group. Any adaptation that would lower total body mass, reduce wing loading, and therefore improve gliding performance would seem appropriate. Unfortunately, the mean bulk density of the 'rhamphorhynchoids' plus or minus one standard deviation (SD $=93.1$ ) spans the bulk densities of both the bird and pterodactlyloid models, rendering the statistical significance of any difference between the three doubtful.

It is sometimes assumed that birds, as flying animals, must have lighter skeletons than terrestrial mammals; however, this is not correct (Schmidt-Nielsen, 1984). A scaling analysis of the fractions of body mass represented by the skeletons of birds and terrestrial mammals (Prange et al., 1979) shows that bird skeletons scale as $0.0649 \cdot \operatorname{mass}_{\mathrm{B}}^{1.068 \pm 0.008 \mathrm{SE}}$, whereas mammal skeletons 

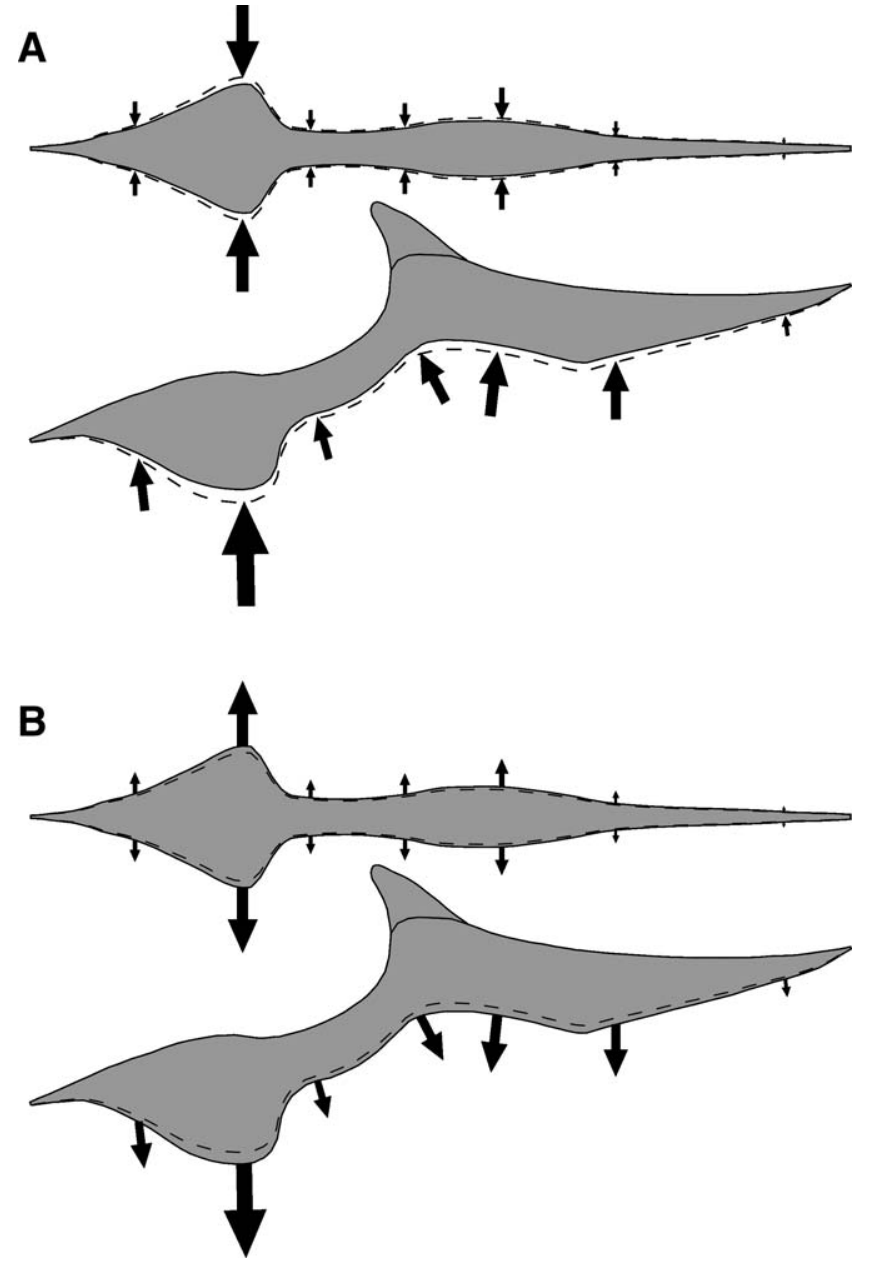

FIGURE 5. Alternative axial body models of Pteranodon longiceps showing how the body shapes were adjusted on all the pterosaur models to produce lighter and heavier versions to test the sensitivity of the model mass estimates to changes in model geometry. The sizes of the arrows indicate the magnitudes of the changes applied to different body regions, and are proportional to the depth and width of the model at the indicated points. The overlain dashed lines show the width and depth of the 'standard' model used in Figure 3E for $P$. longiceps. A, Thin model-total width and depth reduced by $10 \%$. B, Fat model — total width and depth increased by $10 \%$. See online Supplementary Data 1 for details of the actual mass changes resulting from the individual body shape changes.

scale as $0.0608 \cdot \operatorname{mass}_{\mathrm{B}}{ }^{1.083 \pm 0.021 S E}$ (Schmidt-Nielsen, 1984). The coefficients are virtually identical, it is only the slopes that differ. The thinking that birds ought to have lighter skeletons may be reminiscent of how people have perceived pterosaur skeletons to have been associated with bodies of extremely low density. However, a lower overall body density for pterosaurs can arise for purely anatomical reasons. The volumes of the heads and necks of the bird models represent much smaller fractions of total body volume than they do for the pterosaur models- $5.55 \%$ (SD $=6.58 \%)$ for birds versus $32.2 \%(\mathrm{SD}=9.30 \%)$ for pterosaurs. Despite the necks and heads of the two groups being assigned the same densities (300 g/liter), the relatively larger heads and longer, more voluminous necks of the pterosaurs result in these low-density regions offsetting the contribution to bulk density from the relatively smaller, but denser, post-cervical region. The long tails of the 'rhamphorhynchoids' were assigned a high density of $1000 \mathrm{~g} / \mathrm{liter}$, and this will contribute to a small increase in the mean body density.
TABLE 3. Comparisons of the average body densities for the bird and pterosaur models.

\begin{tabular}{|c|c|c|c|}
\hline & $\begin{array}{l}\text { Estimated } \\
\text { total mass } \\
\quad(\mathrm{kg})\end{array}$ & $\begin{array}{l}\text { Total body } \\
\text { volume } \\
\left(\mathrm{m}^{3}\right)\end{array}$ & $\begin{array}{c}\text { Bulk } \\
\text { density } \\
\left(\mathrm{kg} / \mathrm{m}^{3}\right)\end{array}$ \\
\hline \multicolumn{4}{|c|}{ Extant birds } \\
\hline $\begin{array}{l}\text { Wandering Albatross } \\
\text { (Diomedea exulans) }\end{array}$ & 7.36 & 0.00925 & 796 \\
\hline Great Bustard (Otis tarda) & 16.0 & 0.0194 & 824 \\
\hline $\begin{array}{l}\text { Canada Goose (Branta } \\
\text { canadensis) }\end{array}$ & 5.99 & 0.00745 & 804 \\
\hline Ostrich (Struthio camelus) & 80.7 & 0.0947 & 852 \\
\hline $\begin{array}{l}\text { Rock Dove (Pigeon) (Columba } \\
\text { livia) }\end{array}$ & 0.268 & 0.000338 & 794 \\
\hline \multirow{2}{*}{$\begin{array}{l}\text { European Starling (Sturnus } \\
\text { vulgaris) }\end{array}$} & 0.0834 & 0.000109 & 763 \\
\hline & & \multicolumn{2}{|c|}{ Average: $806(\mathrm{SD}=30.1)$} \\
\hline \multicolumn{4}{|c|}{ 'Rhamphorhynchoids' } \\
\hline Anurognathus ammoni & 0.00478 & $6.65 \times 10^{-6}$ & 719 \\
\hline Dimorphodon macronyx & 1.30 & 0.00206 & 630 \\
\hline Eudimorphodon ranzii & 0.325 & 0.000449 & 723 \\
\hline Preondactylus buffarinii & 0.0750 & 0.0000988 & 759 \\
\hline Jeholopterus ninchengensis & 0.0437 & 0.0000587 & 744 \\
\hline Rhamphorhynchus muensteri & 0.986 & 0.00108 & 913 \\
\hline \multirow[t]{2}{*}{ Sordes pilosus } & 0.0758 & 0.000107 & 711 \\
\hline & & \multicolumn{2}{|c|}{ Average: $743(\mathrm{SD}=85.7)$} \\
\hline Pte & lactyloids & & \\
\hline Anhanguera santanae & 6.52 & 0.0105 & 621 \\
\hline Dsungaripterus weii & 10.7 & 0.0150 & 715 \\
\hline Pteranodon longiceps & 18.6 & 0.0283 & 654 \\
\hline Pterodactylus sp. & 0.708 & 0.00108 & 653 \\
\hline Pterodaustro guinaz ui & 0.590 & 0.000826 & 714 \\
\hline Quetz alcoatlus northropi & 544 & 0.751 & 724 \\
\hline \multirow[t]{2}{*}{ Tupuxuara longicristatus } & 22.8 & 0.0336 & 678 \\
\hline & & \multicolumn{2}{|c|}{ Average: $680(\mathrm{SD}=39.3)$} \\
\hline
\end{tabular}

SD, standard deviation.

The widths and depths of the pterosaurian model legs and arms were estimated using a simple linear scaling based on limb bone lengths (see Materials and Methods). However, the resulting widths and depths of the modeled limbs show positive allometric changes with increasing body size, and this is especially noticeable in the differences between the basal arm diameters of Pteranodon longiceps (18.6 kg) and Anhanguera santanae (6.52 kg) (Fig. 3E and B, respectively). Similarly, the smaller 'rhamphorhynchoids' show more slender arms and legs relative to the larger pterodactyloids (Fig. 2). Brower and Veinus (1981) showed that pterosaurian limb bones develop increasing robustness (ratio of overall width to overall length) with increasing size, and the interpretation is that strengths of limb bones and muscles can only keep pace with increasing body mass by increasing their diameters at a slightly faster rate than that of linear body size increase (Alexander, 1985; Brower and Veinus, 1981).

Given that birds and pterosaurs independently evolved powered flight, and both are members of the clade Archosauria, it is of interest to compare the trends of body masses in terms of body length and wingspan between the two groups. Figure $6 \mathrm{~A}$ and $\mathrm{B}$ present $\log -\log$ regression plots of body mass (BM) against body length (BL) and wingspan (WS) for birds and pterosaurs. The resulting regression relationships for birds are $\mathrm{BM}_{\text {birds }}=10.5 \cdot \mathrm{BL}^{2.81 \pm 0.101}$ and $\mathrm{BM}_{\text {birds }}=1.04 \cdot \mathrm{WS}^{2.32 \pm 0.444}$, and for all pterosaurs the results are $\mathrm{BM}_{\text {ptero }}=2.00 \cdot \mathrm{BL}^{2.53 \pm 0.285}$ and $\mathrm{BM}_{\text {ptero }}=0.288 \cdot \mathrm{WS}^{2.66 \pm 0.123}$. The very high mass estimated for Quetzalcoatlus northropi led to its exclusion from the regression analyses. This was done partly to avoid skewing the regression analysis, but also to enable predictions about what body mass would be expected for Quetzalcoatlus northropi based on smaller pterosaurs (see below). Both birds and pterosaurs show 
A

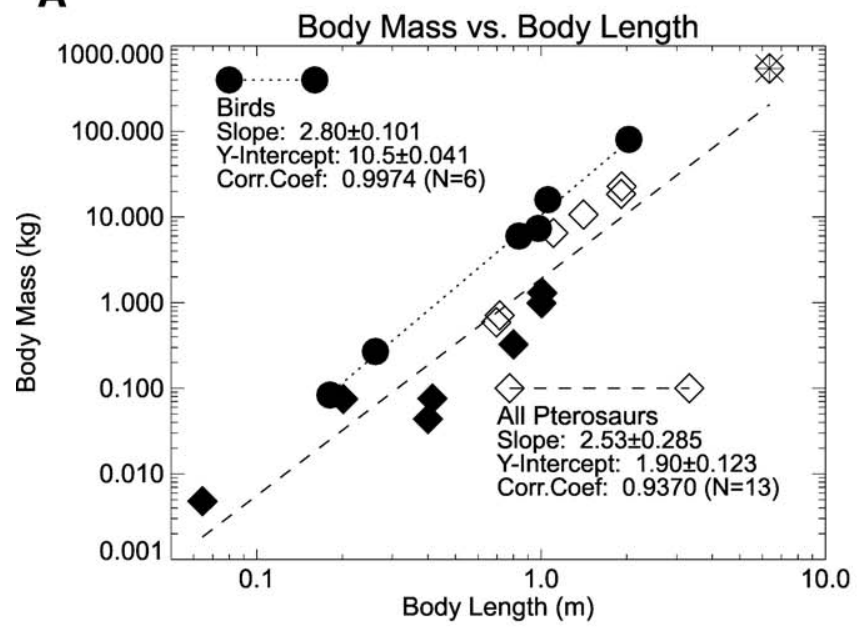

B

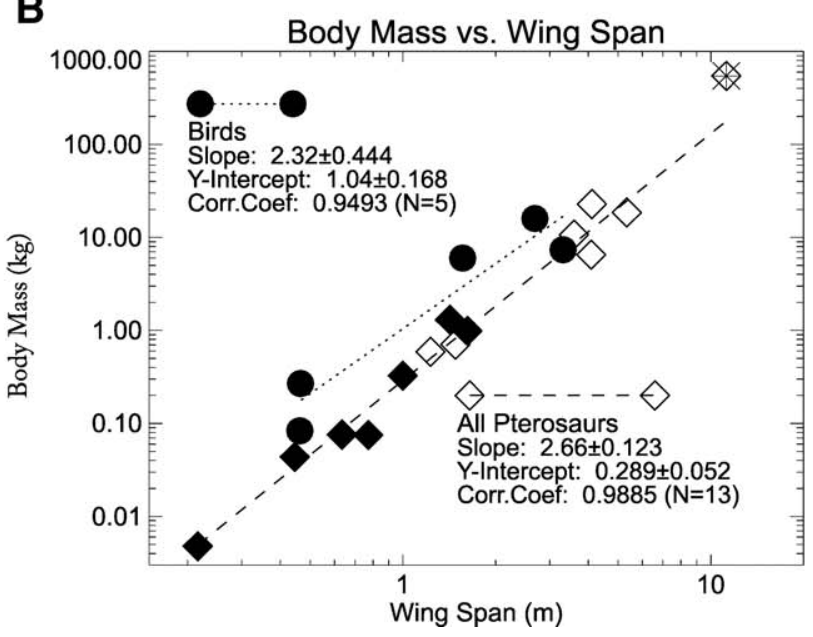

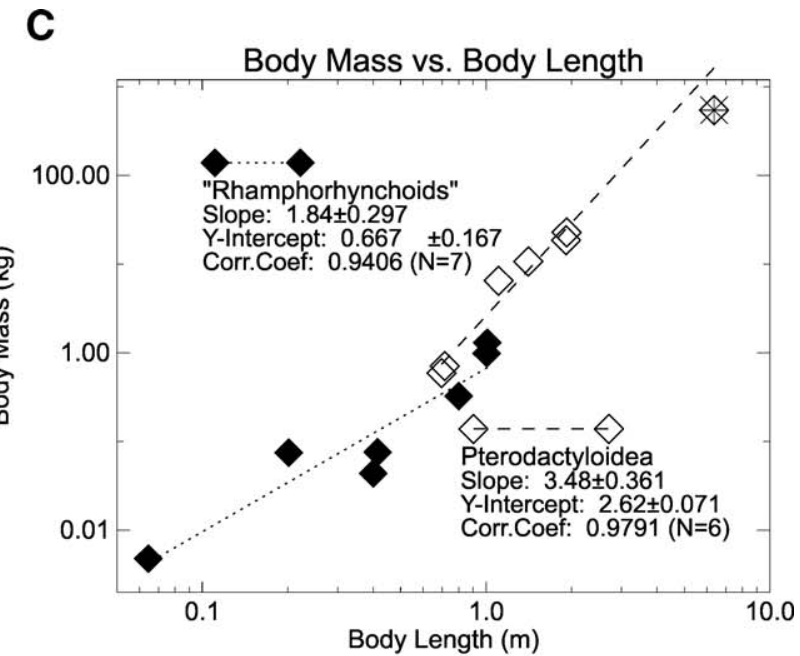

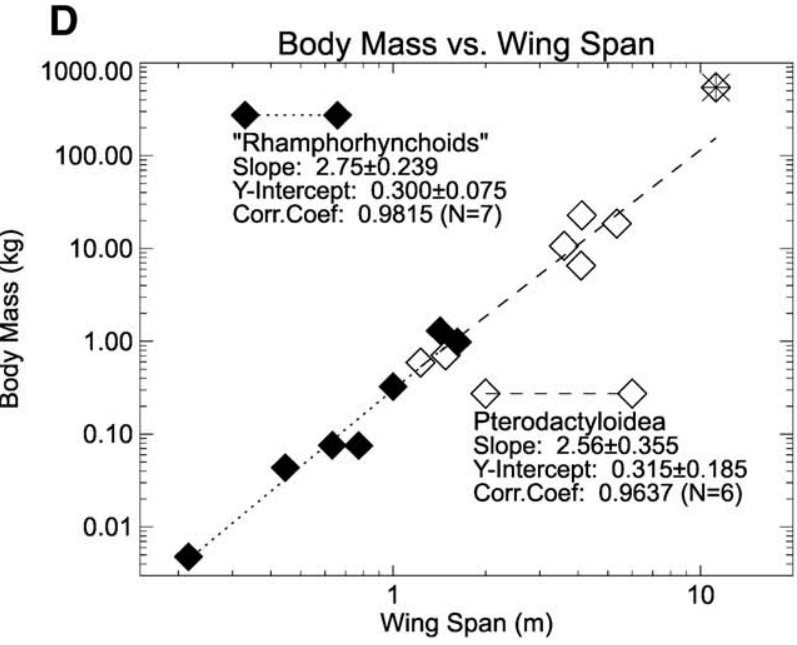

FIGURE 6. Logarithmic regression plots of estimated total body mass against body length and wingspan for the bird (black circles) and pterosaur models ('rhamphorhynchoids'-black diamonds, pterodactyloids - open diamonds). Quetzalcoatlus northropi (indicated by an open diamond shape combined with an asterisk in the extreme upper right of each plot) was excluded from the regression analyses because it is so much larger than any of the other pterosaurs. It was also of interest to see what a regression based on smaller pterosaurs would predict for the mass of Quetzalcoatlus northropi. The ostrich, with its reduced wings, was excluded from plot B. Dotted and dashed lines mark the computed lines of best fit for birds and pterosaurs, respectively, in plots A and B, and for 'rhamphorhynchoids' and pterodactyloids, respectively, in plots C and D.

positive allometry of mass with respect to body length, but in pterosaurs the rate of increase is slightly faster. However, the difference is not statistically significant. A statistically significant difference is the much lower Y-intercept for the mass of pterosaurs, less than $20 \%$ that of birds, and this is a reflection of their much more elongate and attenuated bodies when compared with birds. Even though the bird models include a large flightless bird, the ostrich, the correlation between body mass and body length for the group is very close to unity. The same correlation for the pterosaurs is also high, but not as good as that for birds. In terms of wingspan and body mass, pterosaurs again show a faster rate of increase than birds. Similarly, the Y-intercept of the pterosaurs is less than one third that of the birds, and reflects the lower wing loading estimated for pterosaurs (Bramwell and Whitfield, 1974; Brower and Veinus, 1981; Alexander, 1989). Brower and Veinus (1981) performed similar regression analyses between $\mathrm{BM}, \mathrm{BL}$, and WS for the pterosaur species of their study, but expressed these latter two quantities in terms of body mass $-\mathrm{BL}_{\text {pteros }}=1.64 \cdot \mathrm{BM}_{\text {pteros }}{ }^{0.341}$ and $\mathrm{WS}_{\text {pteros }}=12.2 \cdot \mathrm{BM}_{\text {pteros }}{ }^{0.401}$. Rearranging these two expressions to give $\mathrm{BM}$ in terms of the other two variables gives $\mathrm{BM}_{\text {pteros }}=$ $0.610 \cdot \mathrm{BL}_{\text {pteros }}{ }^{2.93}$ and $\mathrm{BM}_{\text {pteros }}=0.0820 \cdot \mathrm{WS}_{\text {pteros }}{ }^{2.49}$. It can be seen that the exponents arrived at in the present study and those of Brower and Veinus (1981) are extremely close. The principle difference is in the coefficients - those of present study are approximately three times those derived by Brower and Veinus, and reflect the higher densities assigned to the models of the present study. A note of caution is that any scaling relationships based on wingspan will be sensitive to the restored articulations of the forelimbs and the resulting span of the wing.

There are a variety of body sizes and shapes seen among the modeled pterosaurs, and fundamental anatomical differences exist between 'rhamphorhynchoids' and pterodactyloids such as the presence of the long tail in five of the seven 'rhamphorhynchid' models, so performing a single regression analysis on the pterosaur sample does seem very appropriate. 
TABLE 4. Estimated wing loadings for the pterosaur models of Figures 2 and 3.

\begin{tabular}{|c|c|c|c|c|c|}
\hline & Weight (N) & Frontal area $\left(\mathrm{m}^{2}\right)$ & $\begin{array}{l}\text { Axial body frontal } \\
\text { area }\left(\mathrm{m}^{2}\right)\end{array}$ & Full wing area $\left(\mathrm{m}^{2}\right)$ & Loading $\left(\mathrm{N} / \mathrm{m}^{2}\right)$ \\
\hline \multicolumn{6}{|c|}{ 'Rhamphorhynchoids' } \\
\hline Anurognathus ammoni & 0.0469 & 0.00642 & $0.000461(7.18)$ & $0.00596(92.8)$ & 7.31 \\
\hline Dimorphodon macronyx & 12.8 & 0.282 & $0.0205(7.28)$ & $0.262(92.7)$ & 45.2 \\
\hline Eudimorphodon ranzii & 3.19 & 0.145 & $0.0112(7.71)$ & $0.134(92.3)$ & 22.0 \\
\hline Jeholopterus ninchengensis & 0.736 & 0.0562 & $0.00276(4.92)$ & $0.0535(95.1)$ & 13.1 \\
\hline Preondactylus buffarinii & 0.428 & 0.0393 & $0.00279(7.10)$ & $0.0365(92.9)$ & 10.9 \\
\hline Rhamphorhynchus muensteri & 9.68 & 0.355 & $0.0224(6.30)$ & $0.332(93.7)$ & 27.3 \\
\hline Sordes pilosus & 0.744 & 0.0461 & $0.00340(7.37)$ & $0.0427(92.6)$ & 16.1 \\
\hline \multicolumn{6}{|c|}{ Pterodactyloids } \\
\hline Anhanguera santanae & 63.9 & 1.144 & $0.0517(4.52)$ & $1.09(95.5)$ & 55.9 \\
\hline Dsungaripterus weii & 105 & 1.90 & $0.0718(3.77)$ & $1.83(96.2)$ & 55.2 \\
\hline Pteranodon longiceps & 181 & 2.26 & $0.0824(3.65)$ & $2.18(96.4)$ & 80.5 \\
\hline Pterodactylus sp. & 6.94 & 0.260 & $0.0124(4.78)$ & $0.248(95.2)$ & 26.7 \\
\hline Pterodaustro guinaz ui & 5.79 & 0.171 & $0.0116(6.75)$ & $0.160(93.2)$ & 33.8 \\
\hline Quetzalcoatlus northropi & $5.34 \times 10^{3}$ & 14.5 & $1.10(7.58)$ & $13.4(92.4)$ & 369 \\
\hline Tupuxuara longicristatus & 223 & 2.97 & $0.126(4.25)$ & $2.84(95.1)$ & 75.3 \\
\hline
\end{tabular}

Relative fractions of axial and wing areas of the total are shown as percentages in parentheses. See Figure 10.

Figure $6 \mathrm{C}$ and $\mathrm{D}$ repeat the regression analyses of body mass as functions of body length and wingspan for the two pterosaur groups, and gives the following relationships for body mass versus body length: $\mathrm{BM}_{\text {rhamphos }}=0.667 \cdot \mathrm{BL}_{\text {rhamphos }} .84 \pm 0.297$ and $\mathrm{BM}_{\text {pteros }}=$ $2.62 \cdot \mathrm{BL}_{\text {pteros }} 3.48 \pm 0.361$. A slope (exponent) of 3 for a line fitted to a log-log plot of body mass versus body length implies isometric growth (Alexander, 1985), but for the 'rhamphorhynchoids' the exponent is less than two thirds of what would be expected for isometry. This indicates that the modeled 'rhamphorhynchoids' experienced a pattern of phyletic mass increase that emphasized elongation of the body rather than uniformly expanding laterally, dorso-ventrally and axially. In contrast, the pterodactyloids show a phyletic increase in body mass relative to body length with a slope that exceeds that predicted by isometry. This latter group appears to have deepened and widened the body faster than it was lengthened to attain phyletic increases in size (mass). This could be explained by the requirement to maintain a relatively wider and deeper trunk region. Such a trunk would be better able to resist the torsional and compressional stresses associated with the large muscles required to move and control the long arms during flight. This increase in robustness of the axial body with increasing body size parallels what is observed with the proximal limbs bones (Brower and Veinus, 1981). An alternative explanation is that the deeper trunk reflects changes in this region related to respiration and the effective flow of air in an extensive system of thoracic and abdominal air sacs (Claessens et al., 2009). In terms of body mass as a function of wingspan, the scaling relationships derived for the two groups of pterosaurs produce the following relationships (to three significant figures): $\mathrm{BM}_{\text {rhamhos }}$ $=0.300 \cdot \mathrm{WS}_{\text {rhamphos }}{ }^{2.74 \pm 0.239}$ and $\mathrm{BM}_{\text {pteros }}=0.315 \cdot \mathrm{WS}_{\text {pteros }} 2.56 \pm 0.355$. Neither the coefficients, nor the exponents, are significantly different in a statistical sense.

The differing phyletic size change trajectories identified for the 'rhamphorhynchoids' and pterodactyloid models are shown schematically in Figure 7, with the axial body shapes approximated by tri-axial ellipsoids. Three instances of hypothetical growth are illustrated for each group: the initial starting state (0), a middle state arrived after 7 growth increments, and a late state after 15 growth increments. The rate of axial elongation for both groups was arbitrarily set at 1.1 (10\% increase per growth step), but transverse dimensions increased at a low rate of 1.0465 for 'rhamphorhynchoids' and at high rate of 1.1295 for pterodactyloids. These latter rates were derived by numerical experimentation with different rates for transverse growth. The process in- volved estimating masses for a set of 16 ellipsoids representing a growth series, and then determining the regression relationship between log-transformed mass and length data, as was done for the actual models. Growth rates were then adjusted, and the process repeated until the slopes of the regression lines (allometric exponents) were approximately equal to those computed for the models. With these rates of shape change, the allometric exponents for the idealized, pterosaurian tri-axial ellipsoids of Figure 7 come out to 1.9538 and 3.5553 for 'rhamphorhynchoids' and pterodactyloids, respectively, virtually identical to what was observed for the actual body models (within statistical error).

With the availability of mass estimates for the various components of birds and pterosaurs, it was felt that a comparison of relative proportions of the various parts of the models, as fractions of

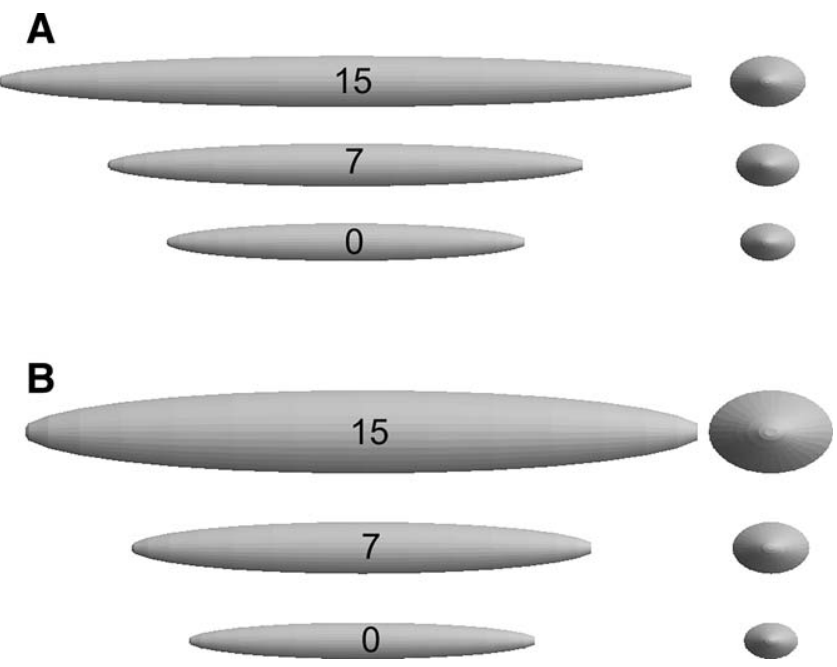

FIGURE 7. Schematic views (lateral and anterior) using elongate triaxial ellipsoids to demonstrate the two different patterns of phyletic size increase identified in the pterosaur models. A, 'Rhamphorhynchoid' trajectory where the rate of axial elongation exceeds that of lateral and dorso-ventral increase in diameter. B, Pterodactlyoid trajectory where the rate of lateral and dorso-ventral expansion exceeds that of axial elongation. The numbers on the models indicate the particular phyletic stages out of the 16 ( 0 through 15$)$ that were used to represent illustrate the change. See Discussion for more detail. 
total mass, might be instructive. These are presented in Figures 8 and 9 for birds and pterosaurs, respectively, and the numbers used to construct these plots are summarized in Appendix 1 for the birds and Table 2 and online Supplementary Data 2 for the pterosaurs. The heads of birds can be seen to represent a much smaller fraction of body mass than is the case for pterosaurs, although a trend shared by both birds and pterosaurs is for the head fraction to decrease with increasing body size. This can be seen in both the bird models of Figure 1, and the graphs of Figures $8 \mathrm{~A}$ and $9 \mathrm{~A}$. However, the trend in pterosaurs is not so well developed, and there are some notable exceptions such as that of Dimorphodon macronyx among the 'rhamphorhynchoids' and Pterodactylus sp. in the pterodactyloids. A substantial difference between the birds and pterosaurs is that the arms and legs of the former represent a larger fraction of body mass than they do in the latter, and the larger the bird the larger the mass fraction of the legs. From the data used to construct the plot in Figure 9B, it can be determined that the average patagial contribution to total mass in 'rhamphorhynchoids' represents more than twice that of pterodactyloids- $8.42 \%$ versus $3.03 \%$. A note of caution regarding these patagial mass fractions is that these estimates are dependent on the estimated thicknesses of the patagia, the densities assigned to them, the reconstructed amount of flexion of the limb bones, and the degree of curvature assigned to the wing fingers, which will determine the areal extents of the wing membranes. Presenting the relative proportions of the components of the models, as well as their local densities, has the benefit of allowing readers to experiment with alternate densities in order to calculate different mass estimates, should they disagree with the choices made here.

Pterosaurs represent the earliest known instance of powered flight by vertebrates (Wellnhofer, 1991a), and an estimation of their wing loading has been a key component of studies of their flight capabilities (e.g., Kripp, 1943; Bramwell and Whitfield, 1974; Brower and Veinus, 1981). The new estimates of body mass and wing area of the present study allow for an analysis of wing loading in the modeled birds and pterosaurs, and these data are presented graphically in Figure 10 and in tabular form in Table 4 for the pterosaurs, and in online Supplementary Data 3 for the birds. Wing loadings for albatross and vultures have been found to lie in the range of $100-150 \mathrm{~N} / \mathrm{m}^{2}$ (Alexander, 1989), and the modeled albatross (Diomedea exulans) and bustard (Otis tarda) have similar values. In general, birds have wing loadings that are proportional to mass ${ }^{0.28}$ (Alexander, 2002), and from the sample of five volant birds studied here, the scaling exponent was found to be 0.21 . For the pterosaur models wing loading was found to scale to body mass raised to the power of 0.309 . Without having to resort to unusually low body densities for the pterosaur models, their wing loadings are all less than those computed for the bird models, in keeping with what previous authors have found (e.g., Bramwell and Whitfield, 1974; Brower and Veinus, 1981; Alexander, 1989). The trend for wing loadings to increase with increasing body size was also identified by Brower and Veinus (1981).

\section{The Strange Case of Quetzalcoatlus northropi}

There are two size classes of Quetzalcoatlus - the formally designated giant one, Quetzalcoatlus northropi (Lawson, 1975), and a smaller form, informally known as Quetzalcoatlus sp. (Kellner and Langston, 1996). The following discussion refers to Q. northropi.

Every since its discovery, the linear dimensions and mass $Q$. northropi have generated controversy (Langston, 1978). Part of the problem is the very incomplete nature of the remains (Lawson, 1975). Mass estimates have ranged from as low as $64 \mathrm{~kg}$ (MacCready, 1985) and $70 \mathrm{~kg}$ (Chatterjee and Templin, 2004) to as high as $250 \mathrm{~kg}$ (Paul, 2002) and $276 \mathrm{~kg}$ (Sato et al., 2009).
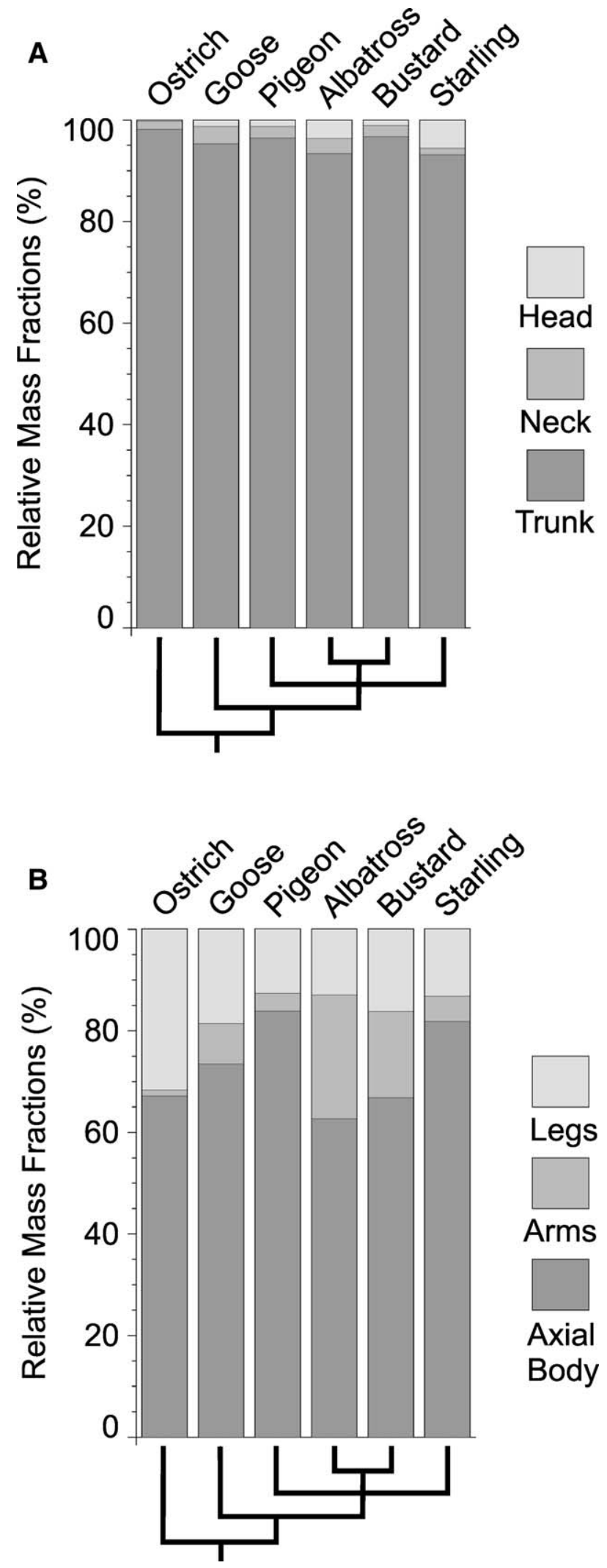

FIGURE 8. Stacked bar graphs illustrating the varying proportions, by mass percentage, of the different regions of the bird models mapped onto cladograms of the inferred relationships among the six species. Upper plot (A) shows only the axial body proportions, whereas the lower plot (B) shows the limbs relative to the axial body. Cladogram is based on Hackett et al. (2008). See Appendix 1 for data used to construct these plots. 


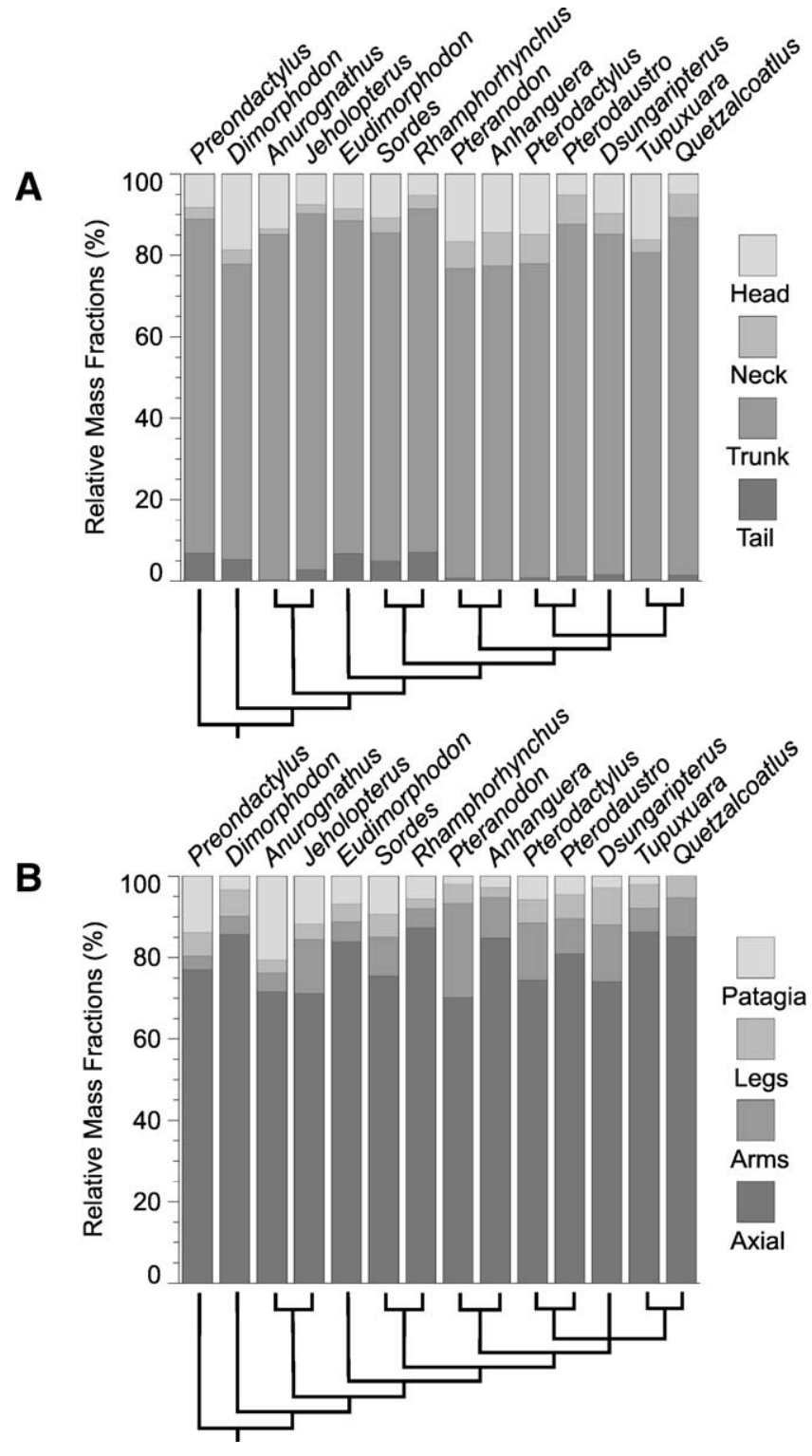

FIGURE 9. Stacked bar graphs illustrating the varying proportions, by mass percentage, of the different regions of the pterosaur models mapped onto a cladogram of the inferred relationships among the 14 species. Upper plot (A) shows only the axial body proportions, whereas the lower plot (B) shows the limbs and patagia relative to the axial body. Cladogram is based on Unwin (2003). See onlne Supplementary Data 2 for data used to construct these plots.

The 64-kg and 70-kg estimates are especially surprising given that they are assigned to pterosaurs with estimated wingspans of $11 \mathrm{~m}$ (MacCready, 1985) and $10.39 \mathrm{~m}$ (Chatterjee and Templin, 2004), respectively. These latter two mass estimates would require the average body densities to be $85 \mathrm{~g} /$ liter and $88 \mathrm{~g} /$ liter, respectively, assuming that they are associated with a pterosaurian body of the same shape and dimensions as that shown in Figure 3G. These densities are difficult to accept in biological terms as they would require that more than $90 \%$ of the body was filled with air. The 64-kg mass estimate was arrived at by consensus between paleontologists and engineers to enable the construction of a half lifesized, robotic model of $Q$. northropi that would be able to fly under its own control (MacCready, 1985). Chatterjee and Templin

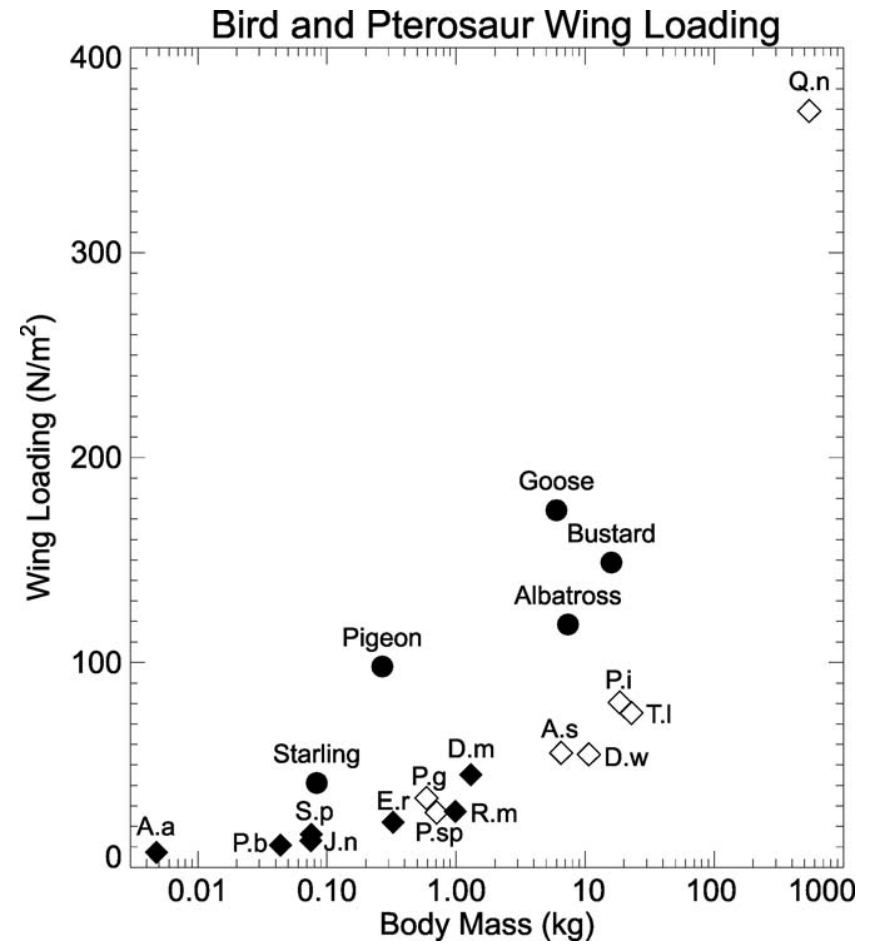

FIGURE 10. Wing loadings computed for the modeled bird and pterosaurs taxa of this study using the estimated masses (multiplied the gravitational acceleration constant of $9.81 \mathrm{~m} / \mathrm{s}^{2}$ ), the combined areas of the wings or patagia and those regions of the axial body between the wings or patagia. Birds, black circles; 'rhamphorhynchoids,' black diamonds; pterodactyloids, open diamonds. See Table 3 for the key to the pterosaur species labels, and Table 6A and B for bird and pterosaur details, respectively.

(2004) considered other mass estimates for Q. northropi for their studies of its flight capability (e.g., $85 \mathrm{~kg}$ and $200 \mathrm{~kg}$ ), and appear to have chosen $70 \mathrm{~kg}$ to make flight by $Q$. northropi plausible. There seems to be a need among some pterosaur workers that $Q$. northropi must be able to fly, and this had led to the generation and acceptance of extremely low mass estimates for such a large animal. These suspicious estimates may arise from the use of nonlinear scaling relationships that are being applied well beyond the ranges that they were originally based upon (Brower and Veinus, 1981; Paul, 2002; Chatterjee and Templin, 2004).

The mass determined with the digital model of $Q$. northropi has the astonishingly high value of $544 \mathrm{~kg}$. There are five ways to react to this estimate: (1) reject it as being beyond the realm of plausibility and a result of a flawed initial restoration; (2) view the result as an indication of a problem with the method of mass estimation; (3) compare the result against some extrapolations using known scaling relationships between body dimensions and mass of a more completely known and related pterosaur; (4) abandon the estimate in favor of lower mass estimates based on other regression relationships; and (5) accept the high mass estimates as within the realm of possibility, and speculate on the implications for the mode of life of a such a large pterosaur. Each of these five options are dealt with below.

The predicted mass for $Q$. northropi, using the regression analysis of mass against body length for the six other pterodactyloids, is a most improbable $1623 \mathrm{~kg}$ (Fig. 6C), and exceeds the modeled mass of $544 \mathrm{~kg}$ by $1079 \mathrm{~kg}$, or $198 \%$. The combination of this unlikely estimate and the mismatch between it and the model mass clearly shows that $Q$. northropi did not attain its large size 
by following the pterodactyloid pattern of phyletic shape change seen in the smaller species. Unfortunately, published data on the skeleton of $Q$. northropi is lacking, except for an incomplete arm and wing finger (Lawson, 1975), and it is to be expected that there will be substantial errors in the shape and size of the model. In particular, the depth of pectoral region, the length of trunk, and the depth and width of the head and neck, could be very different from the current model. The suspect $1632 \mathrm{~kg}$ body-length-based mass prediction highlights the problem of extrapolating nonlinear scaling functions beyond the range upon which they were derived, as the estimated body length of $Q$. northropi is at least three times that of the next largest pterdactyloid-Pteranodon longiceps.

The large gap between the previous high-end mass estimates for $Q$. northropi of $250 \mathrm{~kg}$ (Paul, 2002) and $276 \mathrm{~kg}$ (Sato et al., 2009) and the $544 \mathrm{~kg}$ in this study suggests that there might be something wrong with the method of mass calculation. However, a few simple calculations can show that the result returned by the mathematical slicing method is within the correct range. The average dorso-ventral radius of the trunk region of the $Q$. northropi model is $23.3 \mathrm{~cm}$, the average width is $20.8 \mathrm{~cm}$, and the length is $2.43 \mathrm{~m}$. Using these numbers to approximate the trunk region volume as that represented by a cylinder with an elliptic crosssection gives it a volume of $0.370 \mathrm{~m}^{3}$, and with a uniform density of $850 \mathrm{~kg} / \mathrm{m}^{3}$, a mass of $315 \mathrm{~kg}$. The more precise measure of the mass from the actual dimensions of the trunk is $407 \mathrm{~kg}$. Using just the averages of the trunk depth and width is a rather coarse approximation, but the approximation is only $22.6 \%$ less than the more precisely calculated value. Making similar rough estimates for the neck and head with densities of $300 \mathrm{~kg} / \mathrm{m}^{3}$ gives masses of $27.7 \mathrm{~kg}$ and $19.2 \mathrm{~kg}$, respectively. These approximations of the axial body mass add up to $361 \mathrm{~kg}$, a value just $23.8 \%$ below the more precisely calculated value of $474 \mathrm{~kg}$. With the mathematical slicing method producing reliable mass estimates for the bird models, and the mass estimates for the other pterosaurs similar to what others have found, e.g., Dimorphodon macronyx and Dsungaripterus weii (online Supplementary Data 4), the new mass estimate for $Q$. northropi must be an accurate value given the assumptions that went into the model.

Perhaps the most contentious assumption of the model is the use of a consistent set of density values for all the pterosaur models, independent of body size. There are three reasons for maintaining the same density assignments in the $Q$. northropi model: (1) a consistent set of densities was used for the bird models, and this resulted in plausible mass estimates that spanned three orders of magnitudes, and included both volant and non-volant forms (see Appendices 1 and 2); (2) the estimated masses for the other pterosaur models are not radically different from those of other authors; and (3) there is no direct fossil evidence for dramatic reductions in body density in large pterosaurs. When one starts to choose arbitrarily lower density values because a body mass estimate conflicts with one's expectations, there is no limit to what values could be selected. Until further evidence is made available that indicates otherwise, it would seem that the most scientifically honest and parsimonious option is to apply the same densities to all pterosaurs. If a reader wishes to experiment with other body densities for $Q$. northropi, the mass data in Table 2 can be converted into volumes by dividing by the densities used in the present study. The resulting volumes can then be converted back into masses by multiplying them by alternate density values.

The body mass of $Q$. northropi as a function of its wingspan, again using the six other pterodactyloids as a basis, comes out much lower than that computed directly from the threedimensional model-154 kg versus $544 \mathrm{~kg}$ (Fig. 6D). To have the model body mass match this predicted mass, its average density would have to be reduced to $226 \mathrm{~g} / \mathrm{liter}$. In other words, the entire body would have to be approximately $77 \%$ empty space (air), which does not seem biologically plausible. The wingspan used here for $Q$. northropi, $11.2 \mathrm{~m}$, is based on the conservative estimate suggested by the restoration of Langston (1981), but Lawson (1975) estimated that the wingspan could lie in the range of 11 to $21 \mathrm{~m}$. Despite the limited fossil material available to him at the time, Lawson suggested a value of $15.5 \mathrm{~m}$, and if this is used in the regression equation it gives a mass of $354 \mathrm{~kg}$, which is still just $65 \%$ that of the 'wire-frame' model. The relative proportions of the few preserved wing elements of $Q$. northropi are unlike those of other large pterosaurs (Alexander, 1998), so use of the wingspan-versus-bodymass regression may not be appropriate in this case. Both Brower and Veinus (1981) and Witton (2008) noted that the patterns of allometry for the humerus relative to wingspan were not consistent among different species of pterosaur. The peculiarly short wings of the published restorations of $Q$. northropi are very different from those of the next largest, well-known pterosaur Pteranodon longiceps. The resulting high wing loading estimated for $Q$. northropi using these 11.2$\mathrm{m}$ and $15.5-\mathrm{m}$ wingspans, and the new mass estimates derived from them, would seem to render any flight capability doubtful (Figure 10).

Two other body mass scaling relationships were derived from the models that again use body length and wingspan to predict mass, but these relationships are derived from combining the 'rhamphorhynchoid' and pterodactyloid models, with the exclusion of $Q$. northropi. The body length and wingspan scalings predict masses of $204 \mathrm{~kg}$ and $179 \mathrm{~kg}$, respectively, for Q. northropi, and these values are intermediate relative to those determined by other authors (see above). However, the great range of body and wing shapes exhibited by the models, which get subsumed into the regression, and the implications of all these differences for the various flight styles and modes of life, would appear to undermine any confidence in predictions made from such gross averaging of the various pterosaur bauplans.

There are two simple forms of non-linear scaling that incorporate body proportions of other pterosaurs that can be used to get alternate estimates of the mass of $Q$. northropi. The pterosaur phylogenies of Kellner (2003) and Unwin (2003) both show the Tapejaridae as a sister group to the Azhdarchidae, the clade to which $Q$. northropi belongs. Tupuxuara longicristatus, is a member of theTapejaridae, and the dimensions and mass of the model of this species (Fig. 3A, Tables 1 and 2) can be used for predicting the mass of $Q$. northropi. The first scaling relationship assumes that body mass is proportional to the cube of wingspan (Alexander, 1998), and the following expression:

$$
\frac{22.8 \mathrm{~kg}}{(4.11 \mathrm{~m})^{3}}=\frac{\text { QuetzMass }}{(11.2 \mathrm{~m})^{3}}
$$

gives a mass for $Q$. northropi of $461 \mathrm{~kg}$, a number close to that derived from the model. The second simple form of scaling is to assume that total mass is proportional to the cube of body length (Alexander, 1985). Using T. longicristatus again as the starting point, the expression is:

$$
\frac{22.8 \mathrm{~kg}}{(1.92 \mathrm{~m})^{3}}=\frac{\text { QuetzMass }}{(6.36 \mathrm{~m})^{3}}
$$

and this relation predicts a mass for $Q$. northropi of $829 \mathrm{~kg}$, an estimate even worse in terms of potential flying ability than the model-based 544-kg value. The difference between the two mass estimates from simple scaling demonstrates the hazards of estimation when the exponent is much greater than 1.0. In the wingspan scaling, $Q$. northropi is only 20 times as large as $T$. longicristatus, $\left[20=(11.2 \mathrm{~m} \div 4.11 \mathrm{~m})^{3}\right]$, but in the body length relationship $Q$. northropi is 36 times as large $[36=(6.36 \mathrm{~m} \div 1.92$ $\left.\mathrm{m})^{3}\right]$. It is the long neck of $Q$. northropi, when compared to that 


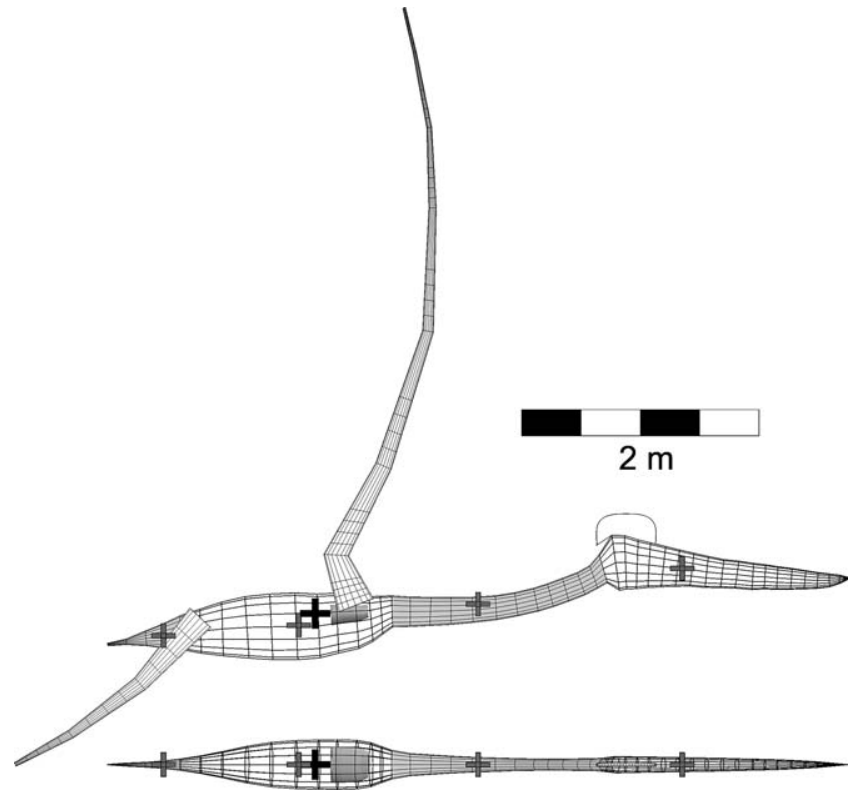

FIGURE 11. 1. Alternate model of Quetzalcoatlus northropi with the body width and depth reduced by $20 \%$ and $25 \%$, respectively, relative to that presented in Figure 3G. Using the same density assignments as for other pterosaurs, the total mass of this thinner model is estimated to be $268 \mathrm{~kg}$.

of $T$. longicristatus, that leads to the excessive mass estimate of $829 \mathrm{~kg}$, and would appear to invalidate the use of $T$. longicristatus as a body-length-based mass predictor for $Q$. northropi.

In an attempt to produce a lighter model of $Q$. northropi, but still retain the same body length and wingspan as that of Figure $3 \mathrm{G}$, an extremely thin version of the axial body was produced (Fig. 11). The widths and depths of all the slices defining the body were reduced by $20 \%$ and $25 \%$, respectively. The resulting width of the body at the level of pectoral region is $42 \mathrm{~cm}$, the maximum width of the skull is $14 \mathrm{~cm}$, and the minimum width of the neck is $9 \mathrm{~cm}$. This model, when given the same density assignments as the other models, and accounting for a lung space, has an axial body mass of $198 \mathrm{~kg}$. The original model had an axial mass of 474 $\mathrm{kg}$. Two questions arise with this model: is there enough internal space for a full suite of air sacs and visceral and sense organs, and is the shape adequate for sufficient musculature of the appropriate force-producing cross-sectional areas to enable take-off and active flight? The extreme narrowness of this model suggests that the answer to both questions is probably 'no.'

Birds arose in the Late Jurassic, and flightless forms such as Hesperornis sp., described by Marsh (1872), and Patagopteryx, described by Alvarenga and Bonaparte (1992), appeared approximately 80 million years ago in the Late Cretaceous. Ignoring the very real possibility that loss of flight in birds occurred earlier, a time lag of approximately 70 million years existed between the first appearance of flying birds and the earliest known appearance of flightless ones. Pterosaurs existed from the Late Triassic until the end of the Cretaceous, an interval of roughly 160 million years. This is the same span of time that birds have existed, and flightless birds have evolved independently many times (Paul, 2002). Is it not possible that a flightless form of pterosaur could have evolved within the immense time span represented by 160 million years?

Could $Q$. northropi be a flightless pterosaur? Accepting this possibility releases us from the requirement to generate, and accept, unrealistically low masses and body densities for such a large animal. It also frees us from the mental gymnastics required to generate an anatomy with sufficient muscle mass and power to be able to fly when possibly weighing more than thirty times that of the heaviest, living, volant birds such as the 16-kg Kori Bustard (Ardeotis kori) and the Great Bustard (Otis tarda), which may attain $22 \mathrm{~kg}$ in some cases (Grzimek et al., 1984). These birds seem to be at the upper mass limit for flying given their apparent difficulty in taking off (Alexander, 1998). A study of the scaling relationships between body mass and the flapping and gliding flight styles in procellariform birds-albatrosses and their closest relatives-predicts an upper body mass limit of $41 \mathrm{~kg}$ for this type of flying (Sato et al., 2009). The largest pterosaurs, species such as Pteranodon longiceps and Anhanguera santanae, are interpreted to have had modes of life similar to those of the Procellariformes - that of sea-going gliders and soarers (Bramwell and Whitfield, 1974; Chatterjee and Templin, 2004; Unwin, 2006). These latter two pterosaurs have estimated body masses that are less than half the predicted 41kg limit (see Table 2). If $Q$. northropi was volant, one would expect a find a range of potentially flight-capable pterosaurs with body sizes between it and the next heaviest pterosaur (Tupuxuara at $22.8 \mathrm{~kg}$ ); instead there is a conspicuous body size gap as seen in figures 4 and 6 . A similar sort of gap exists between the largest volant birds, the bustards, and the flightless ratites, kiwis (Apteryx sp.) excepted. As the unusually low mass estimate based on its relatively short wingspan shows (see above), it appears that $Q$. northropi may have had forelimbs that were unsuited for flight. Having $Q$. northropi as a ground-dwelling pterosaur could explain its extreme size compared to other pterosaurs, because larger walking animals have lower costs of transport (Calder, 1996). Large animals are also better able to resist predation (McGowan, 1991), and a small, flightless pterosaur would have been vulnerable to attack at all stages of its life by the range of small and large, predatory dinosaurs (e.g., dromaeosaurids, oviraptorosaurs, troodontids, tyrannosaurids) inferred to have been sympatric with $Q$. northropi during the Late Cretaceous in North America (Currie, 2005). Extant flightless birds (ostriches, rheas, cassowaries, emus), and many of the volant birds that forage on the ground (shoebills, storks, bustards, secretary birds, vultures), are all much larger than other birds. An analysis of the limb proportions in azhdarchids reveals that they had long hind limbs, and the expectation is that they would have been better at terrestrial locomotion than other pterosaurs (Witton and Naish, 2008). Extensive fossil trackways attributed to extremely large azhdarchid pterosaurs (i.e., forms that must have been similar to $Q$. northropi in size) are known from the Late Cretaceous of Korea (Hwang et al., 2002). These trackways show that the limbs were moved with a parasagittal gait, demonstrating that these large azhdarchids had an effective mode of terrestrial locomotion (Witton and Naish, 2008). Lastly, the remains of Q. northropi have been recovered from rocks that record inland, terrestrial environments (Lawson, 1975), very different from the marine and lacustrine environments that other large pterosaurs are typically associated with (Wellnhofer, 1991a). This habitat difference immediately suggests a very different mode of life for this pterosaur. The idea that Quetzalcoatlus northropi was a secondarily flightless pterosaur ought to be seriously considered.

\section{CONCLUSIONS}

The generation of three-dimensional digital models of pterosaurs enables not only the estimation of their body masses, but also how the body mass is distributed along the axial body and between the limbs for different taxa. Additionally, the mathematical slicing method employed is able to work with the actual restorations, and does not require fitting of regular geometric forms (cylinders, cones, etc.) to approximate body shapes as has been done in the past. A level of confidence in the results 
generated with the pterosaur models is demonstrated by applying the same techniques to models of extant birds, something that has not been done in previous studies of pterosaur body masses. The six bird models employed represent body masses that span three orders of magnitude, yet all lie very close to observed masses of the living forms. This is despite using the same densities for trunk, neck, and head $(850,300$ and $300 \mathrm{~g} /$ liter, respectively) for all models. With the database established with the 14 pterosaur models, regression relationships relating body length and wingspan to body mass were derived for all pterosaurs, and for 'rhamphorhynchoids' and pterodactyloids separately, and these can be used to make provisional estimates of the masses of other pterosaurs that are known from less than adequate fossil material. The extremely large size of the Late Cretaceous form Quetzalcoatlus northropi was highlighted, and it was argued that a pterosaur with a body mass estimated to be 30 times that of the heaviest living flying bird (Kori bustard), and 20 times that of the next heaviest pterosaur modeled (Tupuxuara longicristatus), is better interpreted as a secondarily flightless form.

\section{ACKNOWLEDGMENTS}

I thank James Gardner for his meticulous review of the first draft of the text and figures, Michael Newberry for assistance with the regression statistics, and Michael Dooley and Tai Kubo for bringing the Claessens et al. (2009) and the Sato et al. (2009) papers to my attention. All four are at the Royal Tyrrell Museum of Palaeontology in Drumheller, Alberta, Canada. The criticisms and suggestions of the three reviewers, S. C. Bennett, C. Palmer, and I. M. Anonymous, made for a much-improved paper.

\section{LITERATURE CITED}

Alexander, R. M. 1985. Body support, scaling, and allometry; pp. 26-37 in M. Hildebrand, D. M. Bramble, K. F. Liem, and D. B. Wake (eds.), Functional Vertebrate Morphology. Belknap Press of Harvard University Press, Cambridge, Massachusetts.

Alexander, R. M. 1989. Dynamics of Dinosaurs and Other Extinct Giants. Columbia University Press, New York, 167 pp.

Alexander, R. M. 1998. All-time giants: the largest animals and their problems. Palaeontology 41:1231-1245.

Alexander, R. M. 2002. Principles of Animal Locomotion. Princeton University Press, Princeton, New Jersey, 384 pp.

Alvarenga, H. M. F., and J. F. Bonaparte. 1992. A new flightless landbird from the Cretaceous of Patagonia; pp. 51-64 in K. E. Campbell, $\mathrm{Jr}$ (ed.), Papers in Avian Paleontology Honoring Pierce Brodkord. Natural History Museum of Los Angeles County Science Series 36.

Bennett, S. C. 1991. Morphology of the Late Cretaceous pterosaur Pteranodon and the systematics of the Pterodactyloidea. Ph.D. dissertation. University of Kansas, Lawrence, Kansas, 680 pp.

Bennett, S. C. 2007a. Articulation and function of the pteroid bone of pterosaurs. Journal of Vertebrate Paleontogy 27:881-891.

Bennett, S. C. 2007b. A second specimen of the pterosaur Anurognathus ammoni. Paläontologische Zeitschrift 81:376-398.

Benton, M. J. 1997. Vertebrate Palaeontology, second edition. Chapman and Hall, London, $452 \mathrm{pp}$.

Bonde, N., and P. Christiansen. 2003. The detailed anatomy of Rhamphorhynchus: axial pneumaticity and its implications; pp. 217-232 in E. Buffetaut and J.-M. Mazin (eds.), Evolution and Palaeobiology of Pterosaurs. Geological Society Special Publication 217.

Bramwell, C. B., and G. R. Whitfield. 1974. Biomechanics of Pteranodon. Philosophical Transactions of the Royal Society, Series B 267:503581.

Brower, J. C., and J. Veinus. 1981. Allometry in pterosaurs. The University of Kansas Paleontological Contributions, Paper 105:1-32.

Butler, R. J., P. M. Barrett, and D. J. Gower. 2009. Postcranial skeletal pneumaticity and air-sacs in the earliest pterosaurs. Biology Letters 5:557-560.

Cabe, P. R. 1993. European Starling (Sturnus vulgaris); in A. Poole (ed.), The Birds of North America Online. Cornell Lab of Ornithology, Ithaca, New York. Available at The Birds of North America Online: http://bna.birds.cornell.edu/bna/species/048 doi:10.2173/bna.48. Accessed February 2009.
Calder, W. A. 1996. Size, Function, and Life History. Dover Publications, Inc., Mineola, New York, $431 \mathrm{pp}$.

Chatterjee, S., and R. J. Templin. 2004. Posture, locomotion, and paleoecology of pterosaurs. Geological Society of America, Special Paper 376.

Chiappe, L. M., L. Codorniú, G. Grellet-Tinner, and D. Rivarola. 2004. Argentinian unhatched pterosaur fossil. Nature 432:571572 .

Claessens, L. P. A. M., P. M. O'Connor, and D. M. Unwin. 2009. Respiratory evolution facilitated the origin of pterosaur flight and aerial gigantism. Public Library of Science One 4:1-8.

Currie, P. J. 2005. Theropods, including birds; pp. 367-397 in P. J. Currie and E. B. Koppelhus (eds.), Dinosaur Provincial Park: A Spectacular Ancient Ecosystem Revealed. Indiana University Press, Bloomington, Indiana.

Cuvier, G. 1801. Extrait d'un ouvrage sur les espèces de quadrupèds dont on a trouvé les ossemens dans l'intérieur de la terre. Journal de Physique, de Chimie et d'Histoire Naturelle, 52:253-267.

Deeming, D. C., R. M. Sibly, and I. L. Magole. 1996. Estimation of the weight and body condition of ostriches (Struthio camelus) from body measurements. Veterinary Record 139:210-213.

Greenewalt, C. H. 1975. Could pterosaurs fly? Science 188:676.

Grzimek, H. C. B. 1984. Cranes, bustards, and their relatives; pp. 114-141 in H. C. B. Grizimek, W. Meise, G. Niethammer, and J. Steinbacker (eds.), Grizmek's Animal Life Encyclopedia, Volume 8, Birds II Van Nostrand Reinhold Company, New York.

Hackett, S. J., R. T. Kimball, S. Reddy, R. C. K. Bowie, E. L. Braun, M. J. Braun, J. L. Chojnowski, W. A. Cox, K.-L. Han, J. Harshman, C. J. Huddleston, B. D. Marks, K. J. Miglia, W. S. Moore, F. H. Sheldon, D. W. Steadman, C. C. Witt, and T. Yuri. 2008. A phylogenomic study of birds reveals their evolutionary history. Science 320:1763-1768

Hamershock, D. M., T. W. Seamans, and G. E. Bernhardt. 1993. Determination of the body density for twelve bird species. Report Number WL-TR-93-3049. Flight Dynamics Directorate, Wright Laboratory, AFMC, Wright-Patterson AFB, Ohio 45433-7562; 20 pp.

Hankin, E. H., and D. M. S. Watson. 1914. On the flight of pterodactyls. The Aeronautial Journal 18:324-335.

Hasegawa, Y., K. Carpenter, Z. Dong, and X. Xu. 2006. The Gigantic Dinosaur Expo 2006-Official Guidebook. NHK Promotions Co. Ltd., Tokyo, $186 \mathrm{pp}$.

Hazlehurst, G. A. 1991. The morphometric and flight characteristics of the Pterosauria. Ph.D. dissertation, University of Bristol, Bristol, England, $274 \mathrm{pp}$

Hazlehurst, G. A., and J. M. V. Rayner. 1992. Flight characteristics of Triassic and Jurassic pterosauria: an appraisal based on wing shape. Paleobiology 18:447-463.

Henderson, D. M. 1999. Estimating the mass and centers of mass of extinct animals by 3D mathematical slicing. Paleobiology 25:88-106.

Henderson, D. M. 2002. The eyes have it: the sizes, shapes, and orientations of theropod orbits as indicators of skull strength and bite force. Journal of Vertebrate Paleontology 22:766-778.

Heptonstall, W. B. 1971. An analysis of the flight of the Cretaceous pterodactyl Pteranodon ingens (March) [sic]. Scottish Journal of Geology 7:61-78.

Hwang, K.-G., M. Huh, M. G. Lockley, D. M. Unwin, and J. L. Wright 2002. New pterosaur tracks fro the Late Cretaceous Uhangri Formation, southwestern Korea. Geological Magazine 139:421-435.

Jenkins, F. A., Jr., K. P. Dial, and G. E. Goslow, Jr. 1988. A cineradiographic analysis of bird flight: the wishbone in starlings is a spring. Science 241:1495-1498.

Kellner, A. W. A., and W. Langston, Jr. 1996. Cranial remains of Quetzalcoatlus (Pterosauria, Azhdarchidae) from Late Cretaceous sediments of Big Bend National Park, Texas. Journal of Vertebrate Paleontology 16:222-231.

Kellner, A. W. A. 2003. Pterosaur phylogeny and comments on the evolutionary history of the group; pp. 105-137 in E. Buffetaut and J.-M. Mazin (eds.), Evolution and Palaeobiology of Pterosaurs. Geological Society Special Publication 217.

Ji, Q., S. Ji, Y. Cheng, H. You, J. Lü, Y. Liu, and C. Yuan. 2004. Pterosaur egg with leathery shell. Nature 432:572.

Johnston, R. F. 1992. Rock Pigeon (Columba livia); in A. Poole (ed.), The Birds of North America Online. Cornell Lab of Ornithology, Ithaca, New York. Available at The Birds of North America Online: http://bna.birds.cornell.edu/bna/species/013 doi:10.2173/bna.13. Accessed February 2009. 
Kripp, D. 1943. Ein Lebensbild von Pteranodon ingens auf flugtechnischer Grundlage. Nova Acta Leopoldina N.F. 12, Nr. 82:217240.

Langston, W., Jr. 1978. The great pterosaur. DISCOVERY: Research and Scholarship at The University of Texas at Austin 2(3):20-24.

Langston, W., Jr. 1981. Pterosaurs. Scientific American. February: 122-136.

Lawson, D. A. 1975. Pterosaur from the latest Cretaceous of West Texas: discovery of the largest flying creature. Science 187:947-948.

Li, J., X. Wu, and F. Zhang. 2008. The Chinese fossil reptiles and their kin, second edition. Science Press, Beijing; 473 pp.

Lü, J. 2002. Soft tissue in an early Cretaceous pterosaur from Liaoning Province, China. Memoir of the Fukui Prefecture Dinosaur Museum 1:19-28.

MacCready, P. 1985. The great pterodactyl project. Engineering \& Science, California Institute of Technology 49(2):18 24.

Marsh, O. C. 1872. Preliminary description of Hesperornis regalis, with notices of four other new species of Cretaceous birds. American Journal of Science 3:360-365.

Martill, D. M., and D. M. Unwin. 1989. Exceptionally well-preserved pterosaur wing membrane from the Cretaceous of Brazil. Nature 340:138-140.

Martill, D. M., S. Wenz, P. M. Brito, and P. P. Wilby. 1993. Fossils of the Santana and Crato formations, Brazil Palaeontological Association Field Guide to Fossils, No. 5. London, 159 pp.

McGowan, C. 1991. Dinosaurs, spitfires, and sea dragons. Harvard University Press, Cambridge, Massachusetts; $365 \mathrm{pp}$

Mowbray, T. B., C. R. Ely, J. S. Sedinger, and R. E. Trost. 2002. Canada Goose (Branta canadensis); in A. Poole (ed.), The Birds of North America Online. Cornell Lab of Ornithology, Ithaca, New York. Available at The Birds of North America Online: http://bna.birds.cornell.edu/bna/species/682. Accessed February 2009.

Nowak, R. M., and J. L. Paradiso. 1983. Walker's Mammals of the World, Volume 1, fourth edition. Johns Hopkins University Press, Baltimore, Maryland, $1362 \mathrm{pp}$

Paul, G. S. 2002. Dinosaurs of the Air: The Evolution and Loss of Flight in Dinosaurs and Birds. Johns Hopkins University Press, Baltimore, Maryland, $460 \mathrm{pp}$.

Prange, H. D., J. F. Anderson, and H. Rahn. 1979. Scaling of skeletal mass to body mass in birds and mammals. American Naturalist 113:103-122.
Proctor, N. S., and Lynch, P. J. 1993. Manual of Ornithology: Avian Structure and Function. Yale University Press, New Haven, Connecticut, $340 \mathrm{pp}$.

Prondvai, E., T. Tanács, and E. Frey. 2008. Mass estimate of pterosaurs: a case study on Rhamphorhynchus and the problems of finding the best method. Presented at 6th Meeting of the European Association of Vertebrate Palaeontologists, Spišská Nová Ves, 30 June-5 July 2008

Sato, K., K. Q. Sakamoto, Y. Watanuki, A. Takahashi, N. Katsumata, C.-A. Bost, and H. Weimerskirch. 2009. Scaling of soaring seabirds and implications for flight abilities of giant pterosaurs. Public Library of Science, Volume 4, Issue 4 e5400:1-6.

Schmidt-Nielsen, K. 1984. Scaling: Why is Animal Size So Important Cambridge University Press, Cambridge, U.K., 241 pp.

Stecher, R. 2008. A new Triassic pterosaur from Switzerland (Central Austroalpine, Grisons), Raeticodactylus filisurensis gen. et sp. nov. Swiss Journal of Geosciences 101:185-201.

Unwin, D. M. 2003. On the phylogeny and evolutionary history of pterosaurs; pp. 139-190 in E. Buffetaut and J.-M. Mazin (eds.), Evolution and Palaeobiology of Pterosaurs. Geological Society Special Publication 217.

Unwin, D. M. 2006. The Pterosaurs from Deep Time. PI Press, New York, 347 pp.

Wang, X.-L., and Z. Zhonge. 2004. Pterosaur embryo from the Early Cretaceous. Nature 429:621.

Wellnhofer, P. 1991a. The Illustrated Encyclopedia of Pterosaurs. Salamander Books, London, 192 pp.

Wellnhofer, P. 1991b. Weitere Pterosaurierfunde aus der SantanaFormation (Apt) der Chapada do Araripe, Brasilien. Palaeontographica, A, 215:43-101.

Wilkinson, M. T., D. M. Unwin, and C. P. Ellington. 2006. High lift function of the pteroid bone and forewing of pterosaurs. Proceedings of the Royal Society B 273:119-126.

Witton, M. P. 2008. A new approach to determining pterosaur body mass and its implications for pterosaur flight. Zitteliana B28;143-158.

Witton, M. P. 2009. A new azhdarchoid pterosaur from the Crato Formation (Lower Cretaceous, Aptian?) of Brazil. Palaeontology. 51:1289-1300

Witton, M. P., and D. Naish. 2008. A reappraisal of azhdarchid pterosaur functional morphology and paleoecology. Public Library of Science, Volume 3, Issue 5 e2271:1-16.

Submitted May 17, 2009; accepted October 28, 2009.

APPENDIX 1. Computed results for the bird models of Figure 1.

\begin{tabular}{|c|c|c|c|c|c|c|c|c|}
\hline & $\begin{array}{l}\text { Total mass } \\
\quad(\mathrm{kg})\end{array}$ & $\begin{array}{l}\text { Axial length } \\
(\mathrm{m})\end{array}$ & $\begin{array}{l}\text { Axial mass } \\
(\%)\end{array}$ & $\begin{array}{c}\text { Trunk Mass } \\
(\%)\end{array}$ & $\begin{array}{l}\text { Neck Mass } \\
(\%)\end{array}$ & $\begin{array}{l}\text { Head mass } \\
(\%)\end{array}$ & $\begin{array}{l}\text { Single leg } \\
\text { mass (\%) }\end{array}$ & $\begin{array}{l}\text { Single arm } \\
\text { mass }(\%)\end{array}$ \\
\hline Wandering Albatross & 7.36 & 0.978 & $4.81(65.3)$ & $4.50(61.2)$ & $0.138(1.88)$ & $0.166(2.25)$ & $0.478(6.49)$ & $0.898(12.2)$ \\
\hline Gre & 16.0 & 1.06 & $.3)$ & .1) & $0.235(1.47)$ & $0.113(0.705)$ & $1.30(8.11)$ & $1.35(8.48)$ \\
\hline Ostrich* & 80.7 & 2.04 & $56.0(69.4)$ & $55.1(68.2)$ & $0.867(1.08)$ & $0.107(0.133)$ & $12.9(15.8)$ & $0.472(0.584)$ \\
\hline Rock Dove & 0.26 & 0.262 & $0.234(87.0)$ & $0.225(83.8)$ & $0.00515(1.92)$ & $0.00278(1.04)$ & $0.0170(6.33)$ & $0.00474(1.77)$ \\
\hline European Starling & 0.0834 & 0.181 & $0.0710(85.2)$ & $0.0664(79.6)$ & $0.00088(1.05)$ & $0.00378(4.53)$ & $0.00552(6.63)$ & $0.00208(2.50)$ \\
\hline
\end{tabular}

All masses are in kilograms with relative fractions expressed as percentages of the total mass in parentheses. Trunk includes caudal, pelvic and thoracic regions.

*For the ostrich height range is used instead.

APPENDIX 2. Observed ranges of wingspan and body mass for the bird species used in the mass estimation study.

\begin{tabular}{|c|c|c|c|c|}
\hline & Genus and species & Wingspan range $(\mathrm{m})$ & $\begin{array}{l}\text { Body mass range } \\
(\mathrm{kg})\end{array}$ & Observed variation data source \\
\hline Wandering Albatross & Diomedea exulans & $2.51-3.50$ & $6.25-11.3$ & en.wikipedia.org/wiki/Albatross \\
\hline Great Bustard & Otis tarda & $2.10-2.50$ & $10.0-16.0$ & en.wikipedia.org/wiki/Great_bustard \\
\hline Canada Goose & Branta canadensis & $1.27-1.70$ & $3.0-9.0$ & Mowbray et al. (2002) \\
\hline Ostrich* & Struthio camelus & $1.7-2.00$ & $63.0-130$. & Deeming et al. (1996) \\
\hline Rock Dove (Pigeon) & Columba livia & $0.50-0.67$ & $0.265-0.380$ & Johnston (1992) \\
\hline European Starling & Sturnus vulgaris & $0.31-0.40$ & $.060-0.096$ & Cabe (1993) \\
\hline
\end{tabular}

${ }^{*}$ For the ostrich height range is used instead. 